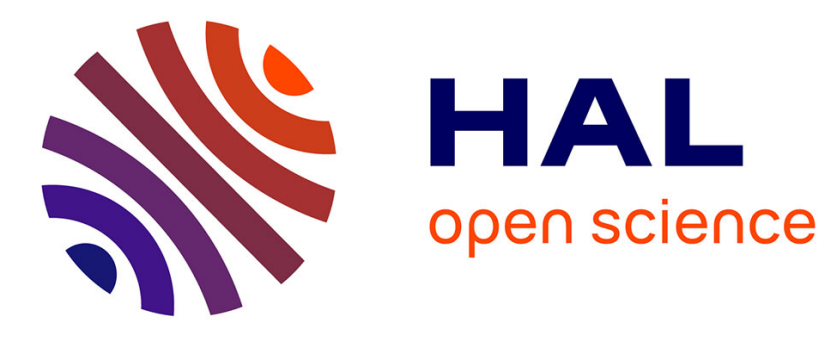

\title{
The welfare impact of global migration in OECD countries
}

\author{
Amandine Aubry, Michal Burzyński, Frédéric Docquier
}

\section{To cite this version:}

Amandine Aubry, Michal Burzyński, Frédéric Docquier. The welfare impact of global migration in OECD countries. Journal of International Economics, 2016, 101, pp.1-21. 10.1016/j.jinteco.2016.03.005 . hal-03481876

\section{HAL Id: hal-03481876 https://hal.science/hal-03481876}

Submitted on 15 Dec 2021

HAL is a multi-disciplinary open access archive for the deposit and dissemination of scientific research documents, whether they are published or not. The documents may come from teaching and research institutions in France or abroad, or from public or private research centers.
L'archive ouverte pluridisciplinaire HAL, est destinée au dépôt et à la diffusion de documents scientifiques de niveau recherche, publiés ou non, émanant des établissements d'enseignement et de recherche français ou étrangers, des laboratoires publics ou privés. 


\title{
The Welfare Impact of Global Migration in OECD Countries*
}

\author{
Amandine Aubry ${ }^{a}$, Michał Burzyński ${ }^{b, c, d}$, Frédéric Docquier ${ }^{b, c}$ \\ ${ }^{b}$ Centre d'Economie de la Sorbonne, Paris School of Economics, Université Paris 1 Pantheon-Sorbonne \\ ${ }^{b}$ IRES, Université Catholique de Louvain $\quad \quad{ }^{c}$ Poznań University of Economics \\ ${ }^{d}$ FNRS, National Fund for Scientific Research
}

March 2016

\begin{abstract}
This paper quantifies the effect of global migration on the welfare of non-migrant OECD citizens. We develop an integrated, multi-country model that accounts for the interactions between the labor market, fiscal, and market size effects of migration, as well as for trade relations between countries. The model is calibrated to match the economic and demographic characteristics of the 34 OECD countries and the rest of the world, as well as trade flows between them in the year 2010. We show that recent migration flows have been beneficial for 69 percent of the non-migrant OECD population, and for 83 percent of non-migrant citizens of the 22 richest OECD countries. Winners are mainly residing in traditional immigration countries; their gains are substantial and are essentially due to the entry of immigrants from non OECD countries. Although labor market and fiscal effects are non-negligible in some countries, the greatest source of gain comes from the market size effect, i.e. the change in the variety of goods available to consumers.
\end{abstract}

Keywords: migration, market size, labor market, fiscal impact, general equilibrium, welfare.

\section{JEL Classification: C68, F22, J24.}

${ }^{*}$ This paper benefited from the helpful suggestions of two anonymous referees. We are also grateful to David de la Croix, Giovanni Facchini, Joël Machado, Krzysztof Malaga, Fabio Mariani, Caglar Ozden and Giovanni Peri for their invaluable comments. We thank the participants of the IRES Macrolunch seminar, the FERDI conference on international migration in Clermont-Ferrand, the GEP postgraduate conference in Nottingham, and the SNF Sinergia-CEPR Conference on "Economic inequality, labor markets and international trade" for their helpful suggestions. Amandine Aubry is grateful for the financial support from the "Fonds spéciaux de recherche" granted by the National Fund for Scientific Research (FNRS). Michal Burzyński thanks the Polish Ministry of Higher Education and Science (Mobility Plus grant) and the National Fund for Scientific Research (FNRS) for their financial support. Corresponding author: Frédéric Docquier, IRES-UCLouvain: frederic.docquier@uclouvain.be. 


\section{Introduction}

International migration has become a sensitive topic in OECD countries. Over the last 50 years, migration movements have drastically affected the socio-demographic characteristics of the 34 OECD member states 1 They have influenced the skill structure of the labor force (impacting wage disparities between groups of workers), the age structure of the population (governing the numbers of net contributors to and net beneficiaries from the welfare state and other public interventions), and the geographical distribution of consumers (with consequences on the aggregate demand for domestic goods and services, number of entrepreneurs, and product varieties available to consumers). The welfare impact of global migration results from the complex interactions between these effects. These interactions are unlikely to be fully internalized by public opinion. They are also imperfectly captured in the academic literature since, with a few exceptions, economists have investigated the transmission channels of migration shocks in isolation.

The objective of this paper is to quantify the impact of the current state of global migration (i.e. inflows of foreigners and outflows of natives) on the welfare of non-migrants living in each OECD country (representing about 96 percent of the native OECD population), and to shed light on the main transmission channels. We use a multi-country framework combining the major economic mechanisms highlighted in the recent literature and accounting for interdependencies between them and between countries. This allows us to assess the relative importance of each channel. The model is parametrized to fit the economic and socio-demographic characteristics of the 34 OECD countries and the rest of the world, as well as the trade flows between them in the year 2010. We then use counterfactual repatriation simulations to identify the between-country and within-country effects of global migration, distinguishing between intra-OECD migration and extra-OECD migration, and between the recent migration flows and the total stocks of migrants.

Assessing the welfare impact of international migration is important. Indeed, recent surveys reveal that worries about migration are on the rise. A majority of respondents in OECD countries see immigration and emigration as sources of problems. ${ }^{2}$ While the perceived channels through which emigration operates are rarely reported, those pertaining to immigration are better documented. In particular, public opinions reflect two major economic concerns, i.e. adverse labor market and fiscal effects of immigration. European Social Survey data for the year 2014 show that only 26.0 percent of European respondents believe that immigrants contribute positively to public finances, and only 35.9 percent think that immigrants create new jobs for natives $\mathrm{3}^{3}$ In the Transatlantic Trends on Immigration 2010, 56 percent of

\footnotetext{
${ }^{1}$ Some stylized facts are described in Appendix A

${ }^{2}$ In 2014, the Transatlantic Trends on Immigration (see http://trends.gmfus.org/) showed that 58 percent of European citizens considered immigration as a problem and not as an opportunity. In the US, this percentage amounted to 31 percent. Worries were particularly important in the case of immigrants from developing countries; in Europe, 56 percent of respondents expressed concerns about extra-EU immigrants, while only 43 percent worried about intra-EU migration. Similarly, 57 percent of Europeans and 28 percent of Americans viewed emigration as a problem.

${ }^{3}$ On a scale from 0 to 10 , these respondents valued a positive contribution of immigration ranging from 6 and 10 . See http://www.europeansocialsurvey.org/.
} 
Americans think that immigrants take jobs away from the native-born, while 44 percent of Europeans think that immigrants bring down the wages of citizens.$^{4}$ These public views are likely to be based on a simplistic vision of the functioning of the economy (e.g. fixed labor demand, perfect substitutability between natives' and migrants' characteristics, immigrants receiving generous welfare benefits, etc.) and a biased estimation of the magnitude of migration flows ${ }^{5}$

The academic literature does not support such perceptions. However, the channels of transmission of migration shocks have usually been studied in isolation, relying on one-country, partial equilibrium frameworks. First, the labor market literature investigates how citizens' wages and employment react to international migration. These effects will be referred to as the labor market effects of migration, henceforth. Recent studies of these labor market effects usually rely on models of aggregate supply and demand for labor, which leave out entrepreneurship and tax responses (see Battisti et al., 2014, Borjas, 2015, Docquier et al., 2014, Ottaviano and Peri, 2012). They show that the wage and employment responses to immigration and emigration are governed by the differences in the socio-demographic characteristics of the native and migrant populations, as well as by the elasticities of substitution between groups of workers as defined by age, education and origin. Second, migrants also contribute to national budgets and collect social transfers. These effects will be referred to as the fiscal effects of migration, henceforth. Studies of the fiscal impact of migration use accounting models with exogenous wages and prices, or general equilibrium models with simple labor market interactions (see Chojnicki, 2013, Chojnicki et al., 2011, Dustmann and Frattini, 2014, Dustmann et al., 2010, Storesletten, 2000) 6 Third, international migration affects the aggregate demand for goods and services in the receiving and sending countries. In a monopolistic competition context, the aggregate demand determines firms' entry and exit decisions and in turn, the numbers of entrepreneurs and goods available to consumers. These effects will be referred to as market size effects of migration, henceforth. They have been understudied in the literature. Borrowing concepts from the recent trade literature, Iranzo and Peri (2009) or Di Giovanni et al. (2015) investigated the welfare impact of market size in a love-of-variety environment à la Krugman (1980) without taxation and with a simple labor market structure. Finally, immigrants and emigrants usually differ from non-migrants in terms of education. Hence, migration directly impacts the average level of schooling in the origin and destination countries, with possible consequences on the level of the total factor productivity. Such TFP effects are more controversial. They have been analyzed in a limited number of empirical studies and mainly pertains to the mobility of high-skilled workers ${ }^{7}$

\footnotetext{
${ }^{4}$ See http://trends.gmfus.org/.

${ }^{5}$ For example, Canadians, Americans and Europeans estimate that 37, 35 and 24 percent of their population are immigrants, while the actual shares are 20,14 and 11 percent, respectively. The differences between the perceived and actual shares cannot be explained by illegal migration or by second-generation immigrants.

${ }^{6}$ In a recent comparative study, the OECD (2013) shows that the fiscal effect of immigration varies across countries; its sign and magnitude are strongly affected by the uncertain effect of migration on public consumption.

${ }^{7}$ For example, Peri et al. (2013) found that immigration flows of scientists, technology professionals, engineers and mathematicians have a significantly positive effect on the wages of college-educated non-migrants in the U.S., and almost no effect on the less educated.
} 
A growing consensus on how to formalize and quantify some of these effects has emerged due to the development of new theoretical foundations and the availability of migration data. However, these effects are interdependent and deserve to be studied jointly. Little is known about their relative magnitudes and their interactions. For example, changes in total factor productivity affect wages, the demand for goods and trade flows. Simultaneously, changes in wage inequality and prices directly influence the fiscal impact of migration, through labor income and consumption tax revenues. In addition, geographical disparities in the production of goods govern the interactions between countries through the incentives to trade. Assessing the welfare impact of migration on non-movers requires accounting for these interactions between countries and between the transmission channels.

The analysis proposed in this paper combines three major transmission channels of migration shocks into an integrated, multi-country model. It ignores the societal implications of immigration (not or indirectly related to economic variables), on which there is no clear consensus in the literature (see Alesina et al. 2013, Borjas, 2015, Collier, 2013). Our setup is an extension of the model proposed by Krugman (1980), augmented with eight classes of individuals (working-age and old, college and non-college educated, immigrants and natives), redistributive taxes and transfers, and complex labor market interactions between natives and migrants. It accounts for the market-size effects initially underlined by Iranzo and Peri (2009) or Di Giovanni et al. (2015). The latter use a love-of-variety, monopolistic competition model with heterogeneous firms à la Melitz (2003) to study the implications of global migration for developed and developing countries. Although Di Giovanni and Levchenko (2013) provide important contributions to the literature on firm heterogeneity, we assume that firms are homogeneous in each country and disregard both the production of intermediate goods and the remittances sent by migrants to their country of origin 8

Our contribution to the existing literature is threefold. First, we combine the labor market, fiscal and market size effects described above in an integrated framework, accounting for the interaction between them. A special attention is devoted to the fiscal effect of migration, which has been disregarded in Iranzo and Peri (2009) and Di Giovanni et al. (2015). The fiscal effect will prove to be important in some countries. We will also account for schooling externalities in our robustness analysis. Second, we calibrate the model to perfectly fit the economic and demographic characteristics of the 34 OECD countries and those of the rest of the world, as well as the trade flows between them in the year 2010. In particular, distinguishing between eight classes of individuals, our model captures the effect of migration on the age structure of the population. Third, we consider richer numerical experiments. We analyze the effect of total migration versus recent migration (i.e. migrants who arrived between 2000 and 2010) and

\footnotetext{
${ }^{8}$ Assuming heterogeneous firms and intermediate inputs has both advantages and disadvantages. On the one hand, this might provide a more realistic representation of macro and micro features highlighted by the recent trade literature. On the other hand, it requires to define firm preferences towards intermediate goods and demand a precise calibration of the parameters of the distribution of firm productivity and size. The former is difficult to model in a one-sector framework and usually imposes a strong assumption of identical preferences for consumers and firms. The literature is still in its early stages concerning the latter and, due to data limitation, has essentially focused on the United States.
} 
distinguish between intra-OECD and extra-OECD migration. This allows us to quantify the effect of each channel, to identify the dominant ones, and to compare the between- and within-country redistributive effects of migration.

The effect of global migration on welfare is computed using two counterfactual experiments: a repatriation of recent migrants to their home countries, and a repatriation of the total stock of migrants (as if the legal barriers for migration, for example the visa costs, had been infinitely large over the last ten years or over the last century, respectively). We quantify the overall economic impact for the high-skilled and the low-skilled non-movers, and identify the relative contribution of the three main channels described above: the labor market, market-size, and fiscal effects. ${ }^{9}$ We also account for schooling externalities in the robustness section.

Using estimated elasticities from the empirical literature, we show that recent migration flows induced many winners and a few losers among OECD citizens ${ }^{10}$ As stated above, we distinguish between 8 groups of individuals per country. The set of winners represents 69.1 percent of OECD non-migrant population aged 25 and over. This share increases to 83.0 percent if one considers the 22 countries whose GDP per capita was above USD 30,000 in the year 2010. Contrary to popular perceptions, winners mainly reside in net immigration countries; their gains can be important and are essentially due to the entry of immigrants from non-OECD countries, which has a drastic effect on market size. Losers mostly reside in net emigration countries; welfare losses are smaller (except in relatively poorer countries such as Mexico, Turkey, Estonia or Poland) and are essentially due to the (intra-OECD) emigration of their nationals. However, for these traditional emigration countries, we overestimate the magnitude of the losses because we disregard remittance inflows (accounting for 2.1, 0.8 and 0.2 percent of GDP in the year 2010 in Mexico, Poland and Turkey, respectively). Although labor market and fiscal effects are important sources of variability across countries, the market-size effect is a significant source of welfare gains. On average, the market-size effect increases the welfare of all workers by 1.0 percent in the OECD, whereas the average fiscal effect equals 0.4 percent, and the average labor market effect equals 0.1 percent for college graduates and 0.2 percent for the less educated ${ }^{11}$

Very similar results are obtained if trade is ruled out, if we change the fiscal rule, or if we let the elasticities of substitution between varieties vary within the range of values provided in the empirical literature. Larger effects can be obtained if we allow for schooling externalities on total factor productivity, or if we change the elasticity of substitution between native and immigrant workers in production. In addition, we also evaluate the effect of global migration stocks as if all past waves of migration had been nil. Although the average magnitude of the effect becomes greater and we identify more losers, the

\footnotetext{
${ }^{9}$ In general, our analysis focuses on the welfare impact on the non-movers, because this is the group that has the voting power and decides on migration and fiscal policies.

${ }^{10}$ In a previous version of this paper, we calibrated the model on the year 2000, and simulated the effects of a repatriation of the 1990-2000 migration wave. Similar results were obtained, available upon request.

${ }^{11}$ In an earlier version of this paper, we quantified the impact of global migration between 1990 and 2000 and obtained very similar conclusions. Overall, most OECD citizens benefited from South-North migration, intra-OECD migration was a zero-sum game, and the market size effect was instrumental to explaining these effects.
} 
market-size effect remains important. It increases the welfare of all workers by 2.6 percent in the OECD. This is greater than the average fiscal effect (1.2 percent) and the average labor market effect ( 0.2 percent for the less educated and - 0.4 percent for college graduates). In line with Di Giovanni et al. (2015), we find that the market size is instrumental to explaining the welfare consequences of migration.

The remainder of the paper is organized as follows. In Section 2, we present the theoretical model. The quantitative analysis is provided in Section 3 . It describes the calibration strategy, our benchmark findings, and the results of a large set of robustness checks. Section 4 concludes.

\section{Theoretical model}

We develop a static, multi-country model endogenizing the economic effect of global migration (i.e. inflows of foreigners and outflows of natives) on the welfare of non-migrants in OECD countries. Three channels of influence are taken into consideration in the benchmark model: the labor market effect, the fiscal effect, and changes in the mass of horizontally differentiated products available to consumers. We model the competitive labor market effect as in Docquier et al. (2014), the fiscal effect as in Storesletten (2000) or Chojnicki et al. (2011), and the market-size effect using the "love-of-variety" model of Krugman (1980). The latter endogenizes the mass of varieties produced in a country as a function of the market size. By changing the mass and the type of consumers in origin and destination countries, migration affects the aggregate demand for goods, the mass of entrepreneurs, and the available product diversity. The "love-of-variety" model has been used extensively to quantify the large effect of the tradeinduced growth in product variety on welfare (see Broda and Weinstein, 2006). Although the model has no physical capital, we model the effect of migration on firm creation and entrepreneurship investments (each entrepreneur incurs a fixed cost of entry) ${ }^{12}$ Countries are interdependent: the economic effects are propagated across countries through endogenous trade flows.

Our model is static and includes $C$ countries indexed by $c \in\{1,2, \ldots, C\}$. Each country is populated by 8 groups of individuals. We denote the individual's skill/origin type by $m \in\{H, L, h, l\}$ and the individual's cohort by $a \in\{w, r\}$, and we assume that all agents have identical preferences. Total population in country $c$ is made of $L_{w, c}^{T}$ working-age individuals and $L_{r, c}^{T}$ retirees. Each group is divided into four types of individuals: $L_{w, c}^{L}$ and $L_{r, c}^{L}$ low-skilled natives, $L_{w, c}^{H}$ and $L_{r, c}^{H}$ high-skilled natives, $L_{w, c}^{l}$ and $L_{r, c}^{l}$ low-skilled immigrants, and $L_{w, c}^{h}$ and $L_{r, c}^{h}$ high-skilled immigrants. We use superscript $S$ when aggregating high-skilled natives and foreigners $(H, h)$, and subscript $U$ when aggregating the less educated $(L, l)$. Individuals are assumed to be homogeneous within each group; we thus disregard heterogeneity based on unobservable characteristics, and assume that all immigrant workers in a given skill cell are perfect substitutes on the labor market.

\footnotetext{
${ }^{12}$ Capital adjustments are rapid in open economies. ? find that an exogenous inflow of immigrants increases one-for-one employment and capital stocks in the receiving country in the short term (i.e. within one year), leaving the capital/labor ratio unchanged.
} 
The demographic structure is considered as exogenous, since we aim to quantify the "causal" impact of migration flows on income (as in Di Giovanni et al., 2015, Docquier et al., 2014). Within a skill and age cell, individuals differ only in terms of income and place of residence, governing their access to local and foreign varieties. In this section, we describe the preferences and technologies used to endogenize consumers' and firms' decisions. We then characterize the monopolistically competitive equilibrium of the global economy.

\subsection{Preferences and consumers' decisions}

The preferences of a representative consumer of type $m \in\{H, L, h, l\}$ and cohort $a \in\{w, r\}$ living in country $c$ are identical across types of consumers. They are described by a CES utility function over a continuum of varieties indexed by $k$ :

$$
U_{a, c}^{m}=\left(\sum_{j \in C} \int_{0}^{B_{j}} q_{a, c j}^{m}(k)^{\frac{\epsilon-1}{\epsilon}} d k\right)^{\frac{\epsilon}{\epsilon-1}}
$$

where $q_{a, c j}^{m}(k)$ stands for the quantity of variety $k$ produced in country $j$ and consumed in country $c$ by an agent of type $m$ and cohort $a$, and $B_{j}$ is the mass of varieties produced in country $j$. Varieties are imperfect substitutes, characterized by a constant elasticity of substitution equal to $\epsilon>113$

Labor supply is exogenous and we do not model savings decisions, assuming that each individual consumes her income entirely ${ }_{14}^{14}$ Workers' nominal income is the sum of group-specific net wages and public transfers; retirees only receive public transfers. Hence, the utility function (1) is maximized subject to a static budget constraint:

$$
\sum_{j \in C} \int_{0}^{B_{j}} \widetilde{p}_{c j}(k) q_{a, c j}^{m}(k) d k=\widetilde{\omega}_{a, c}^{m},
$$

where $\widetilde{p}_{c j}$ defines the gross price of variety $k$ produced in country $j$ and consumed in $c$. In particular, every consumer pays a consumption tax in her country of residence, hence: $\widetilde{p}_{c j}(k)=\left(1+v_{c}\right) p_{c j}(k)$, where $v_{c}$ is the consumption tax rate in country $c$ and $p_{c j}(k)$ is the before-tax price of good $k$. Variable $\widetilde{\omega}_{a, c}^{m}$ represents the net nominal income of an individual of type $m$ and cohort $a$ who lives in country $c$. The CES preferences induce that she spends all her income on consumption, and every available variety

\footnotetext{
${ }^{13}$ We follow the traditional model of Krugman $(1980)$ by supposing that foreign and domestic products enter symmetrically in the utility function and are subject to the same elasticity of substitution.

${ }^{14}$ The elasticity of labor supply to wages is usually found to be small (Evers et al. 2008). However, endogenizing labor supply matters if the participation rates of natives and immigrants are strongly different. A recent OECD report (OECD. 2015) indicates that immigrants from developing countries exhibit smaller participation rates than natives in Europe (in particular, lowskilled women from Muslim countries). Although these immigrants represent a small fraction of the working-age population, accounting for differences in participation rates can attenuate the magnitude of the labor market and market size effects. Dealing with heterogeneous participation rates is a non-trivial extension, which requires a more general utility function with leisure, and calibrating origin-specific preference parameters (i.e. relaxing the hypothesis of homogeneous preferences).
} 
faces a positive demand (i.e. $\lim _{q_{a, c j}^{m}(k) \rightarrow 0} \partial U_{a, c}^{m} / \partial q_{a, c j}^{m}(k)=\infty$ ).

The demand function derived from the first-order condition of this maximization problem is written:

$$
q_{a, c j}^{m}(k)=\frac{P_{c}^{\epsilon-1}}{\widetilde{p}_{c j}(k) \epsilon} \widetilde{\omega}_{a, c}^{m},
$$

where $P_{c}$ denotes the ideal price index in country $c$ and is defined as:

$$
P_{c}=\left[\sum_{j \in C} \int_{0}^{B_{j}} \widetilde{p}_{c j}(k)^{1-\epsilon} d k\right]^{\frac{1}{1-\epsilon}} .
$$

The latter expression reflects the underlying love-of-variety property of the CES utility function. Given that $\epsilon>1$, a greater mass of varieties tends to lower the value of the ideal price index and to increase the individual's welfare (keeping the consumer's expenditure unchanged). Intuitively, under CES preferences, the ideal price index can be seen as an indicator of (optimized) costs of living. Indeed, the individual's indirect utility function is given by:

$$
U_{a, c}^{m}=\left(\sum_{j \in C} \int_{0}^{B_{j}}\left(\frac{P_{c}^{\epsilon-1}}{\widetilde{p}_{c j}(k)^{\epsilon}} \widetilde{\omega}_{a, c}^{m}\right)^{\frac{\epsilon-1}{\epsilon}} d k\right)^{\frac{\epsilon}{\epsilon-1}}=\frac{\widetilde{\omega}_{a, c}^{m}}{P_{c}}
$$

with $\frac{\partial P_{c}}{\partial B_{j}}<0$ and so $\frac{\partial U_{a, c}^{m}}{\partial B_{j}}>0$.

From eq. (3), we derive the demand function faced by each firm in country $c, q_{c}(k)$, and the total expenditure function in country $c, X_{c}$ :

$$
q_{c}(k)=\sum_{j \in C} \sum_{m, a} L_{a, j}^{m} q_{a, j c}^{m}(k) \quad \text { and } \quad X_{c}=\sum_{m, a} L_{a, c}^{m} \sum_{j \in C} \int_{0}^{B_{j}} \tilde{p}_{c j}(k) q_{a, c j}^{m}(k) d k .
$$

\subsection{Technology and firms' decisions}

In each country $c$, there is a mass $B_{c}$ of firms that operate on a monopolistically competitive market. Therefore, strategic interdependencies between firms are ruled out. Production requires labor, which is supplied inelastically by the four types of imperfectly substitutable workers. The labor market is perfectly competitive, so that each type of worker is remunerated according to her marginal productivity. Obviously, in countries with restrictive institutions, many factors hamper wage adjustments, which result in adjustments in the employment rate (see Angrist and Kugler, 2003, Aydemir and Kirdar, 2013, Glitz, 2012). This issue mainly pertains to low-skilled workers living in European countries, where wage rigidities are stronger. In our general equilibrium setting, there is no unemployment and we do not deal with the heterogeneity between employed and unemployed workers, conjecturing that the effect of migration on the aggregate wage bill (and on market size effects) does not depend too much on the type of 
labor market adjustment ${ }^{15}$ Contrary to Di Giovanni et al. (2015), we assume that firms are homogeneous in productivity within a country and that labor is the unique production factor.

Each firm maximizes its profit, which then leads to the decision to enter the market or not, and what price to set once in. For the sake of clarity, we separately describe the two related sides of the profit maximization problem, i.e. the minimization of the unit cost of production for a given level of output, and the determination of the optimal price and output. We first describe the former, which enables us to highlight the labor demand for each type of worker, as well as the aggregate labor demand. We continue with the latter which allows us to derive the pricing rule and the optimal output per firm.

\subsubsection{Production function}

The production function of firm $k$ in country $c$ is defined as a nested CES combination of labor. The upper-level production function determines the quantity of high-skilled and low-skilled workers needed to produce $y_{c}(k)$, and is specified as:

$$
y_{c}(k)=A_{c} \bar{\ell}_{c}^{T}(k)=A_{c}\left(\theta_{c}^{S}\left(\bar{\ell}_{c}^{S}(k)\right)^{\frac{\sigma_{S}-1}{\sigma_{S}}}+\left(1-\theta_{c}^{S}\right)\left(\bar{\ell}_{c}^{U}(k)\right)^{\frac{\sigma_{S}-1}{\sigma_{S}}}\right)^{\frac{\sigma_{S}}{\sigma_{S}-1}}
$$

where $A_{c}$ is the country-specific level of total factor productivity (TFP), $\bar{\ell}_{c}^{T}(k)$ is total employment in efficiency units by firm $k$, which divides into $\bar{\ell}_{c}^{S}(k)$ and $\bar{\ell}_{c}^{U}(k)$, total employment of high-skilled and low-skilled labor in efficiency units. Each factor is defined in terms of efficiency units to account for the inherent productivity of each type of worker and the benefits resulting from the interactions between workers. The elasticity of substitution, $\sigma_{S} \in(1, \infty)$, captures the imperfect substitutability between workers of different education levels. Parameter $\theta_{c}^{S}$ reflects the relative productivity of high-skilled labor.

Moreover, it is well documented that conditional on education, immigrants and natives are imperfect substitutes. Recent papers (such as Manacorda et al., 2012, Ottaviano and Peri, 2012) find imperfect degrees of substitution between these two types of workers. To account for this, we define the efficient labor supply for each level of education as a CES function of native and immigrant employment:

$$
\begin{aligned}
& \bar{\ell}_{c}^{U}(k)=\left[\theta_{c}^{M}\left(\ell_{c}^{L}(k)\right)^{\frac{\sigma_{M}-1}{\sigma_{M}}}+\left(1-\theta_{c}^{M}\right)\left(\ell_{c}^{l}(k)\right)^{\frac{\sigma_{M}-1}{\sigma_{M}}}\right]^{\frac{\sigma_{M}}{\sigma_{M}-1}}, \\
& \bar{\ell}_{c}^{S}(k)=\left[\theta_{c}^{M}\left(\ell_{c}^{H}(k)\right)^{\frac{\sigma_{M}-1}{\sigma_{M}}}+\left(1-\theta_{c}^{M}\right)\left(\ell_{c}^{h}(k)\right)^{\frac{\sigma_{M}-1}{\sigma_{M}}}\right]^{\frac{\sigma_{M}}{\sigma_{M}-1}},
\end{aligned}
$$

where the country-specific $\theta_{c}^{M}$ is a parameter of relative productivity of national workers, and $\sigma_{M} \in$

\footnotetext{
${ }^{15}$ Endogenizing unemployment would also affect the fiscal impact of migration (through unemployment benefits). This effect is expected to be small. On average, unemployment benefits represent 1.24 percent of GDP in OECD countries. Most of the fiscal cost of immigration is driven by the effect of migration on old-age, health and public education expenditures.
} 
$(1, \infty)$ is the elasticity of substitution between national and foreign workers. We constrain the nativeimmigrant elasticity to be the same across education levels. Indeed, to the best of our knowledge, there is no consensus on the elasticities of substitution within each group once we relax this constraint. For instance, Card (2009) finds that less-educated immigrants and natives are closer to perfect substitutes than skilled immigrants and natives. Ottaviano and Peri (2012) report opposite results.

\subsubsection{Optimal labor demand}

The before-tax nominal wage rate for a worker of type $m \in\{H, L, h, l\}$ is denoted by $w_{c}^{m}$. Since the labor market is competitive, firms take $w_{c}^{m}$ as given. The ideal (composite) wages of efficient low-skilled and high-skilled workers, denoted by $W_{c}^{U}$ and $W_{c}^{S}$, and the ideal composite aggregate wage, denoted by $W_{c}$, result from the cost minimization described below. Since high-skilled workers are, on average, more productive, we have $W_{c}^{S}>W_{c}^{U}$; and within each skill category, nationals are usually better paid than immigrants (reflecting, for instance, the imperfect transferability of skills across countries): $w_{c}^{H}>w_{c}^{h}$ and $w_{c}^{L}>w_{c}^{l}$.

The optimal labor demand allocated to the production process is determined by a two-stage cost minimization. First, for a given production level $y_{c}(k)$, each firm chooses the optimal combination of high-skilled and low-skilled workers that minimizes the total labor cost:

$$
\begin{gathered}
\min _{\bar{\ell}_{c}^{S}(k), \bar{\ell}_{c}^{U}(k)} W_{c}^{S} \bar{\ell}_{c}^{S}(k)+W_{c}^{U} \bar{\ell}_{c}^{U}(k) \\
\text { s.t. } A_{c}\left(\theta_{c}^{S}\left(\bar{\ell}_{c}^{S}(k)\right)^{\frac{\sigma_{S}-1}{\sigma_{S}}}+\left(1-\theta_{c}^{S}\right)\left(\bar{\ell}_{c}^{U}(k)\right)^{\frac{\sigma_{S}-1}{\sigma_{S}}}\right)^{\frac{\sigma_{S}}{\sigma_{S}-1}} \geq y_{c}(k) .
\end{gathered}
$$

The first-order conditions determine the optimal demand for efficient low-and high-skilled workers in firm $k$ :

$$
\bar{\ell}_{c}^{S}(k)=\frac{y_{c}(k)}{A_{c}}\left(\frac{\theta_{c}^{S} W_{i}}{W_{c}^{S}}\right)^{\sigma_{S}} \quad \text { and } \quad \bar{\ell}_{c}^{U}(k)=\frac{y_{c}(k)}{A_{c}}\left(\frac{\left(1-\theta_{c}^{S}\right) W_{c}}{W_{c}^{U}}\right)^{\sigma_{S}},
$$

where $W_{c}$ is the ideal labor cost index, defined as:

$$
W_{c}=\left[\left(\theta_{c}^{S}\right)^{\sigma_{S}}\left(W_{c}^{S}\right)^{1-\sigma_{S}}+\left(1-\theta_{c}^{S}\right)^{\sigma_{S}}\left(W_{c}^{U}\right)^{1-\sigma_{S}}\right]^{\frac{1}{1-\sigma_{S}}}
$$

Equations (9) show that the demand for each type of worker increases with $y_{c}(k)$, and decreases with the composite labor cost for this type of worker. Due to the imperfect substitution between inputs, the labor demand for each skill level is a function of all input prices (through the aggregate wage index $W_{c}$ ). Hence, the higher the elasticity of substitution between the two types of workforces, $\sigma_{S}$, the higher the demand for the relatively cheaper type of labor.

Second, each firm chooses the optimal combination of national and foreign workers within each 
education category, taking the total supply of efficient high- and low-skilled labor as given (see eq. (9)). Firms solve the following cost minimization for high-skilled workers:

$$
\begin{gathered}
\min _{\ell_{c}^{H}(k), \ell_{c}^{h}(k)} w_{c}^{H} \ell_{c}^{H}(k)+w_{c}^{h} \ell_{c}^{h}(k) \\
\text { s.t. }\left(\theta_{c}^{M}\left(\ell_{c}^{H}(k)\right)^{\frac{\sigma_{M}-1}{\sigma_{M}}}+\left(1-\theta_{c}^{M}\right)\left(\ell_{c}^{h}(k)\right)^{\frac{\sigma_{M}-1}{\sigma_{M}}}\right)^{\frac{\sigma_{M}}{\sigma_{M}-1}} \geq \bar{\ell}_{c}^{S}(k) .
\end{gathered}
$$

The optimal labor demand for skilled natives and migrants is then equal to:

$$
\begin{aligned}
\ell_{c}^{H}(k) & =\bar{\ell}_{c}^{S}(k)\left(\frac{\theta_{c}^{M} W_{c}^{S}}{w_{c}^{H}}\right)^{\sigma_{M}} \\
& =\frac{y_{c}(k)}{A_{c}}\left(\frac{\theta_{c}^{S} W_{c}}{W_{c}^{S}}\right)^{\sigma_{S}}\left(\frac{\theta_{c}^{M} W_{c}^{S}}{w_{c}^{H}}\right)^{\sigma_{M}},
\end{aligned}
$$

and

$$
\begin{aligned}
\ell_{c}^{h}(k) & =\bar{\ell}_{c}^{S}(k)\left(\frac{\left(1-\theta_{c}^{M}\right) W_{c}^{S}}{w_{c}^{h}}\right)^{\sigma_{M}} \\
& =\frac{y_{c}(k)}{A_{c}}\left(\frac{\theta_{c}^{S} W_{c}}{W_{c}^{S}}\right)^{\sigma_{S}}\left(\frac{\left(1-\theta_{c}^{M}\right) W_{c}^{S}}{w_{c}^{h}}\right)^{\sigma_{M}},
\end{aligned}
$$

where $W_{c}^{S}$ is the remuneration of the ideal high-skilled labor cost composite described by eq. 99, which we refer to as the ideal wage index for the high-skilled:

$$
W_{c}^{S}=\left[\left(\theta_{c}^{M}\right)^{\sigma_{M}}\left(w_{c}^{H}\right)^{1-\sigma_{M}}+\left(1-\theta_{c}^{M}\right)^{\sigma_{M}}\left(w_{c}^{h}\right)^{1-\sigma_{M}}\right]^{\frac{1}{1-\sigma_{M}}}
$$

The labor demand and wage index for low-skilled natives and migrants are derived in a symmetric way and lead to the following ideal wage index:

$$
W_{c}^{U}=\left[\left(\theta_{c}^{M}\right)^{\sigma_{M}}\left(w_{c}^{L}\right)^{1-\sigma_{M}}+\left(1-\theta_{c}^{M}\right)^{\sigma_{M}}\left(w_{c}^{l}\right)^{1-\sigma_{M}}\right]^{\frac{1}{1-\sigma_{M}}} .
$$

The homogeneity of firms induces that $\ell_{c}^{S}(k)=\ell_{c}^{S}$ and $\ell_{c}^{U}(k)=\ell_{c}^{U}$ for all $k$. For the sake of clarity, we will then drop index $k$ henceforth. Summing these values across all firms gives the aggregate labor demand for each type of worker.

The cost minimization problem described above determines the optimal unit cost of production for each firm:

$$
C_{c}=\frac{w_{c}^{H} l_{c}^{H}+w_{c}^{h} l_{c}^{h}+w_{c}^{L} l_{c}^{L}+w_{c}^{l} l_{c}^{l}}{y_{c}}=\frac{W_{c}}{A_{c}},
$$

as well as the labor demand for the share of the workforce allocated to the production process and the total labor demand in the economy. 
Notice that not all human resources are devoted to the production process, since each firm in country $c$ faces a fixed entry cost, $f_{c}$, to enter the domestic market ${ }^{16}$ We follow the "new trade" literature by expressing fixed costs in units of efficient labor composite ${ }^{17}$ These costs can be interpreted as an investment that a firm must make to explore the market and differentiate its product. Therefore, the aggregated demand for labor also includes the one for workers who are employed for investment purposes. The amount of efficient labor required to create a mass $B_{c}$ of firms (i.e. the fixed cost of entry) equals $B_{c} f_{c}$. Their total cost amounts to $B_{c} f_{c} W_{c}$. The total share of efficient labor devoted to creating firms is then $\xi \equiv \frac{f_{c} B_{c} W_{c}}{W_{c} L_{c}^{T}}=\frac{1}{\epsilon}$ and the remaining share $1-\xi$ (i.e. $\frac{\epsilon-1}{\epsilon}$ ) of workers is employed to produce the final good ${ }^{18}$ Therefore, the efficient labor per firm, $\bar{\ell}_{c}^{T}$, can be written as:

$$
\bar{\ell}_{c}^{T}=\frac{\epsilon-1}{\epsilon} \frac{\bar{L}_{c}^{T}}{B_{c}}
$$

Consequently, given that the share of labor allocated to firm creation is constant, the total efficient labor demand in the economy is defined as:

$$
\bar{L}_{w, c}^{T}=B_{c}\left(f_{c}+\bar{\ell}_{c}^{T}\right)
$$

The labor market clearing conditions imply that the aggregate labor demand for each type of worker $m \in\{L, H, l, h\}$ equals the exogenously given country endowment $L_{w, c}^{m}$.

$$
\begin{aligned}
& L_{w, c}^{L}=\bar{L}_{w, c}^{T}\left(1-\theta_{c}^{S}\right)^{\sigma_{S}}\left(\theta_{c}^{M}\right)^{\sigma_{M}}\left(W_{c}\right)^{\sigma_{S}}\left(W_{c}^{U}\right)^{\sigma_{M}-\sigma_{S}}\left(w_{c}^{L}\right)^{-\sigma_{M}}, \\
& L_{w, c}^{H}=\bar{L}_{w, c}^{T}\left(\theta_{c}^{S}\right)^{\sigma_{S}}\left(\theta_{c}^{M}\right)^{\sigma_{M}}\left(W_{c}\right)^{\sigma_{S}}\left(W_{c}^{S}\right)^{\sigma_{M}-\sigma_{S}}\left(w_{c}^{H}\right)^{-\sigma_{M}}, \\
& L_{w, c}^{l}=\bar{L}_{w, c}^{T}\left(1-\theta_{c}^{S}\right)^{\sigma_{S}}\left(1-\theta_{c}^{M}\right)^{\sigma_{M}}\left(W_{c}\right)^{\sigma_{S}}\left(W_{c}^{U}\right)^{\sigma_{M}-\sigma_{S}}\left(w_{c}^{l}\right)^{-\sigma_{M}}, \\
& L_{w, c}^{h}=\bar{L}_{w, c}^{T}\left(\theta_{c}^{S}\right)^{\sigma_{S}}\left(1-\theta_{c}^{M}\right)^{\sigma_{M}}\left(W_{c}\right)^{\sigma_{S}}\left(W_{c}^{S}\right)^{\sigma_{M}-\sigma_{S}}\left(w_{c}^{h}\right)^{-\sigma_{M}} .
\end{aligned}
$$

\subsubsection{Optimal price and output}

The firm's profit maximization determines the price and quantity produced per firm. Each firm produces a differentiated product and the love-of-variety assumption implies that each variety is consumed. At the same time, since we assume a continuum of firms, the effect of the pricing rule of each firm on the demand for another product is negligible. Therefore, each firm faces a residual demand curve with a

\footnotetext{
${ }^{16} \mathrm{We}$ assume that firms have perfect information about the costs of entry, thus they will be indifferent between paying the one-time investment $\operatorname{cost} \bar{f}_{c}$ and the amortized, discounted, per-period portion of this cost $f_{c}=\bar{f}_{c} / d_{c}$. In a dynamic framework, $d_{c}$ would be the expected age of a firm operating in country $c$.

${ }^{17}$ Expressing fixed costs in units of efficient labor has an impact on the size of the global gains from migration. Indeed, Iranzo and Peri (2009) formalize entry costs as a fixed amount of output that cannot be sold. They obtain a stronger effect of migration on productivity since, on average, migrants move to more efficient economies with lower fixed costs. Measuring fixed costs in units of output complicates the model and would reinforce our main conclusion that the between-country effects exceed the within-country ones.

${ }^{18} \mathrm{We}$ assume that both the marginal entrepreneur and the marginal worker are remunerated identically, so that these two agents are indifferent between being employed and starting a firm.
} 
constant elasticity of substitution equal to $\epsilon$ and then chooses the same markup $\epsilon /(\epsilon-1)$ which yields the following pricing rule:

$$
p_{c}=\frac{\epsilon}{\epsilon-1} C_{c}=\frac{\epsilon}{\epsilon-1} \frac{W_{c}}{A_{c}}
$$

where $C_{c}$ is the marginal cost of production defined by eq. (15). Moreover, a firm from country $j$ can export its product to country $c$, but faces an iceberg trade $\operatorname{cost} \tau_{c j}>1 \forall c \neq j$ if it does so. Hence, the before-tax price paid by consumers in country $c$ for the goods produced in country $i$ equals to $p_{c j}=p_{j} \tau_{c j}$ $\forall c \neq j$. Due to the love-of-variety property of the preferences, each firm exports to all foreign markets as long as the trade cost is finite.

The output per firm, $y_{c}$, is determined by profit maximization and the free entry condition. Indeed, when gains are positive, new firms enter the market, causing profits to fall, until they are driven to zero. In equilibrium, the profit of each firm is equal to zero:

$$
\pi_{c}=\left(p_{c}-C_{c}\right) y_{c}-W_{c} f_{c}=0
$$

By replacing the price by its value defined in eq. (18) in the zero profit condition, we derive the output per firm:

$$
y_{c}=(\epsilon-1) A_{c} f_{c}
$$

Finally, we compute the mass of varieties $B_{c}$ produced in economy $c$ as a function of country size. To do so, we define the total production in economy $c$, that is $B_{c} y_{c}$. We then substitute eq. 16) for $\bar{\ell}_{c}^{T}$ into eq. (7) and equalize it to the value defined in eq. (20):

$$
B_{c} y_{c}=B_{c} A_{c} \bar{\ell}_{c}^{T}=A_{c} \frac{\epsilon-1}{\epsilon} \bar{L}_{c}=B_{c}(\epsilon-1) A_{c} f_{c} .
$$

The mass of varieties produced in a given country is then equal to:

$$
B_{c}=\frac{\bar{L}_{w, c}^{T}}{\epsilon f_{c}}
$$

This result is similar to the one derived by Krugman (1980). The equilibrium number of firms in a particular country is proportional to the size of the country (measured here in efficiency units), $\bar{L}_{c}^{T}$, and inversely proportional to the fixed cost, $f_{c}$. In line with the recent literature (see Helpman et al., 2008), we assume a country-specific entry cost. Therefore, a reallocation of the population across countries may change the aggregate mass of varieties. Indeed, if the workforce moves to countries with a lower entry cost, the aggregate mass of varieties increases, potentially enhancing global welfare.

Given the zero profit condition, the goods market clearing condition implies that the total spending $X_{c}$ defined in eq. (6) equals the value of domestic production. Finally, by aggregating the country-pairspecific expenditures, $p_{c j} q_{c j}$ from eq. (3), we obtain a simple representation of the exports from country 
$j$ to country $c$ as a function of the trade $\operatorname{cost} \tau_{c j}$ :

$$
\frac{X_{c j}}{X_{j}}=\frac{X_{c}\left(P_{c} / \tau_{c j}\right)^{\epsilon-1}}{\sum_{i=1}^{C} X_{i}\left(P_{i} / \tau_{c i}\right)^{\epsilon-1}} .
$$

\subsection{Government}

Fiscal policy consists of two tax rates (a consumption tax rate $v_{c}$, and a labor income tax rate $t_{c}$ ), a vector of type- and age-specific levels of public spending per inhabitant, $G_{a, c}^{m}$, and a vector of type- and age-specific transfers per inhabitant, $T_{a, c}^{m}$. The consumption tax rate increases the price of a good by a factor of $1+v_{c}$, as shown in eq. (2). Natives and immigrants are taxed at the same rate, but differ with respect to their impact on public finances. Typically, $G_{a, c}^{m}$ includes final public expenditures, assumed to be identical for all groups of residents, and children's education expenditures, which are only allocated to working-age parents and vary with their education level and origin (immigrants versus natives). Public transfers $T_{a, c}^{m}$ include public health expenditures, family allowances, pension benefits, unemployment and other welfare payments; their amounts vary with age, education and origin. Public consumption and transfers are not taxed. Our fiscal bloc is a static version of Storesletten (2000) and Chojnicki et al. (2011), except we do not link pension benefits to wages and we rule out budget deficits.

Working-age individuals consume their net-of-tax labor income and transfers, whereas retirees do not work and only consume the transfers they receive from the government. We have:

$$
\begin{aligned}
\widetilde{\omega}_{w, c}^{m} & =w_{c}^{m}\left(1-t_{c}\right)+T_{w, c}^{m} \forall m, \\
\widetilde{\omega}_{r, c}^{m} & =T_{r, c}^{m} \forall m .
\end{aligned}
$$

As far as public consumption is concerned, we assume that the government allocates public spending between goods as consumers do (see eq. (3)). In the benchmark scenario, we also assume that $v_{c}$, $G_{a, c}^{m}$ and $T_{a, c}^{m}$ are exogenous for all $a, m, c$, and that the labor income tax rate $t_{c}$ adjusts to balance the government budget, as in Chojnicki et al. (2011). The budget constraints is written as:

$$
\sum_{m} L_{w, c}^{m} t_{c} w_{c}^{m}+\sum_{m} L_{w, c}^{m} v_{c}\left(1-t_{c}\right) w_{c}^{m}+\sum_{m, a} L_{a, c}^{m} v_{c} T_{a, c}^{m}=\sum_{m, a} L_{a, c}^{m} T_{a, c}^{m}+G_{a, c}^{m}
$$

In the benchmark scenario, we consider that the amount of public goods provided by the government is constant per person. This means that the aggregate production of public goods increases with population size (e.g. national defense, justice, and public infrastructure). Assuming a constant amount per person, we avoid large fiscal externalities linked to changes in population size. In line with Storesletten (2000) or Chojnicki et al. (2011), public consumption does not directly affect utility or productivity.

In the robustness check, we will consider an alternative scenario, assuming that all public spending is fixed, i.e. is not affected by population size (consider for example national defense or foreign affairs). 
Therefore, immigration allows sharing the cost of these goods among a greater number of individuals (a positive fiscal externality of migration), while emigration has the opposite effect. We will also consider a scenario with adjustments in the consumption tax rate, instead of the income tax rate.

\subsection{Monopolistic competitive equilibrium}

In the benchmark scenario, we have:

Definition 1. For a set of common parameters $\left\{\epsilon, \sigma_{S}, \sigma_{M}\right\}$, a set of country-specific parameters $\left\{\theta_{c}^{S}\right.$, $\left.\theta_{c}^{M}, A_{c}, f_{c}, v_{c}, T_{a, c}^{m}, G_{a, c}^{m}\right\}_{c \in C}$, the matrix of country-pair trade costs $\left[\tau_{c j}\right]_{c, j \in C}$, and country-specific numbers of people in the young and old generations, $L_{a, c}^{m}$, the monopolistically competitive equilibrium is a set $\left\{w_{c}^{m}, W_{c}, W_{c}^{S}, W_{c}^{U}, C_{c}, q_{c}, p_{c}, P_{c}, B_{c}, t_{c}\right\}_{c \in C}$ and $\left[X_{c j}\right]_{c, j \in C}$ such that the following conditions are satisfied: (i) consumers maximize their utility, (ii) firms maximize profits, (iii) the goods and factor markets clear, (iv) profits are equal to zero, and (v) the government budget is balanced in each economy $c \in C$. These conditions are reflected by the set of equations (3), (4), (10), (13), (14), (15), (17), (18), (21), 22), and (23).

When budget constraints are balanced and the goods and factor markets clear, the Walras law guarantees the equilibrium of the balance of payments for each country $c$ (i.e. $\sum_{j} X_{c j}=\sum_{j} X_{j c} \forall c \in C$ ). Alternative scenarios with endogenous total factor productivity, alternative fiscal rules or an absence of trade will be considered in the robustness checks.

\subsection{Disentangling welfare changes}

The proposed model enables us to decompose the indirect utility function of working-age individuals and retirees of type $m$ in country $c$, defined as the net income deflated by the ideal price index in eq. (5), as follows:

$$
\begin{aligned}
\frac{\Delta U_{w, c}^{m}}{U_{w, c}^{m}} & =\frac{w_{c}^{m}\left(1-t_{c}\right)}{w_{c}^{m}\left(1-t_{c}\right)+T_{w, c}^{m}}\left[\frac{\Delta w_{c}^{m}}{w_{c}^{m}}+\frac{\Delta\left(1-t_{c}\right)}{\left(1-t_{c}\right)}\right]-\frac{\Delta P_{c}}{P_{c}}, \\
\frac{\Delta U_{r, c}^{m}}{U_{r, c}^{m}} & =-\frac{\Delta P_{c}}{P_{c}} .
\end{aligned}
$$

The total change in welfare is then divided into four components altered by migration, the three main effects at work and a fourth one capturing general equilibrium interdependencies between them:

(i) The labor market effect is the most common channel highlighted in the literature. A change in the size and in the composition of the labor force must affect the nominal wages of heterogeneous agents $\left(w_{c}^{m}\right)$, due to the fact that low- and high-skilled workers, as well as natives and migrants, are imperfect substitutes. By changing the skill structure of the labor force, migration changes the marginal productivity of non-migrant workers. In particular, low-skilled immigrants increase the wages of highskilled workers and reduce the wages of their counterparts. Emigration leads to opposite effects. 
(ii) The fiscal effect forms another channel which is identified in our model. Using eq. 23], we quantify the extent to which migration affects the labor income tax rate $\left(t_{c}\right)$. The latter operates through a change in the number of beneficiaries and contributors to the fiscal scheme. The fiscal effect pertains to all workers but not to retirees, as we assume constant transfers per person.

(iii) The market-size effect operates through changes in the mass of entrepreneurs and varieties produced in all countries. This induces variations in the ideal price index $\left(P_{c}\right)$, a weighted combination of domestic and foreign prices. Other things equal, an increase in the mass of varieties produced in country $c$ leads to a fall in the price index, as reflected in eq. (4). Moreover, global migration may increase the total available mass of varieties, if the population moves towards more efficient economies (i.e. countries with lower entry costs or higher productivity), as shown in eq. (21). Therefore, in the presence of trade, the sending countries could gain from migration if the aggregate mass of varieties increases. Due to the presence of trade costs, this increase in demand is biased towards domestic varieties (at least if the wage differences across countries do not offset this advantage).

(iv) As nominal wages affect marginal costs and prices, interdependencies arise between channels. The difference between the total effect and the sum of the labor market, fiscal and market-size effects, taken in isolation, is referred to as the general equilibrium effect.

To quantify the relative magnitude of each transmission channel, we proceed as follows. First, for each type of worker, the labor market effect is computed as the change in the nominal wage caused by global migration. Given the interdependencies between the transmission channels, wage responses affect prices (through eq. (18)) and the income tax rate (through the fiscal base). To calculate the magnitude of the market-size and fiscal effects, we need to neutralize these interdependencies using partial equilibrium simulations. Second, we thus isolate the market-size effect by computing the response of the price index induced by the change in aggregate demand, keeping nominal wages and tax rates constant (therefore, the government budget constraints and labor market equilibria are violated). Third, we isolate the fiscal effect by computing the change in the income tax rate, keeping nominal wages and the mass of varieties constant (i.e. violating the government balances). Finally, the general equilibrium effect is computed as a residual (i.e. difference between the total welfare change and the sum of the three other effects taken in isolation).

\section{Quantitative analysis}

In this section, we calibrate the parameters of the model, using country-specific data and insights from the existing literature, and then describe the results of our numerical experiments. We explain our calibration strategy and examine its relevance in Section 3.1. Section 3.2 discusses our benchmark results. Finally, we conduct a large set of robustness checks in Section 3.3 . 


\subsection{Parametrization}

We calibrate our model for the 34 OECD countries and the rest of the world (ROW), the aggregation of all non-OECD countries, for the year 2010. This section describes our data sources and the approach used to calibrate the common and country-specific parameters.

Population data - Our model is static and our objective is study how the size and the structure by age and education of international migration affects the economy and the welfare of citizens in the OECD countries. We combine two data sources that allow us to characterize the effects of the stocks of recent and older migrants on the structure of the population in the year 2010. Obviously, other aspects of immigrants are likely to affect their contributions to the economy (such as the quality of education, age of arrival, return intentions, fertility, longevity, etc.) and are disregarded here. We use population data from the United Nations ${ }^{19}$ The database documents the total and immigrant populations of all countries by age group and by year. We extracted the 2000 and 2010 data for each OECD member state and we aggregated the rest of the world. We distinguish between the two age categories in our model, individuals aged 25 to 64 (the working-age group) and individuals aged 65 and over (the retirees).

As for the education structure of the population, we use the Database on Immigrants in OECD countries (DIOC) described in Arslan et al. (2015). The data are collected by country of destination and are mainly based on population censuses or administrative registers. The DIOC database provides detailed information on the demographic characteristics, level of education and labor market outcomes of the population of OECD member states. For the 2000 and 2010 census rounds, we extract information about the country of origin, age, and educational attainment. This allows us to quantify the bilateral stocks of immigrants from all world countries and the numbers of non-migrants in all OECD countries by education (college graduates and the less educated) and by age (25 to 64 , and 65 and over) ${ }^{20}$ These DIOC stocks are then rescaled to match the aggregate population data of the United Nations, giving our measures of $L_{a, c}^{m}$. For the rest of the world, we do not distinguish between natives and residents and use the population data from the United Nations, and the education data from Barro and Lee (2013).

Table B1 in the Appendix B gives the structure of the population aged 25 and over for all OECD member states in the year 2010. As far as emigration is concerned, we estimate the number of emigrants from each OECD member state by aggregating the bilateral stocks of migrants across destinations, by education level and age. Clearly, the size and structure of the population would have been different if all migrants had been unable to leave their home country. For each OECD country, Table B2 shows the impact of global migration stocks (i.e. stocks of immigrants and emigrants) on the proportion of foreigners, on the old-age dependency ratio, and on the share of college graduates in the labor force in

\footnotetext{
${ }^{19}$ See: http://www.un.org/en/development/desa/population/migration/data/estimates2/estimatesage.shtml.

${ }^{20}$ Censuses sometimes account for undocumented immigrants, at least in some countries like the US. This is not the case in Europe. The Clandestino database gives lower-bound and upper-bound estimates of the stock of illegals in EU countries (see Kraler and Rogoz, 2011). These percentages are usually low. In addition, these data do not have any information on the origin, education levels, and age of migrants. For these reasons, we chose to ignore illegal migration.
} 
the year 2010.

As far as migration flows are concerned, we proceed as in Docquier et al. (2014) or Artuc et al. (2015), and proxy net migration flows over the period 2000-2010 by taking the difference between the stock in 2010 and the stock in 2000. As individuals usually move at a young age, we only consider the difference in the stock of migrants aged 25 to 64 . The size and structure of the population would have also been different if these recent immigrants and emigrants had been unable to move. For each OECD country, Table B3 shows the impact of the 2000-10 net migration flows on the proportion of foreigners, on the old-age dependency ratio, and on the share of college graduates in the labor force. Finally, Figure B1 compares the effect of global migration stocks (horizontal axis) and global migration flows (vertical axis) on population size, old-age dependency, and human capital. Although the effects of the stocks exceed by far the effects of the flows, they are strongly correlated (correlation rates of $0.70,0.51$ and 0.53 for population, dependency and human capital, respectively).

Fiscal data - To calibrate fiscal policy, we combine three databases. First, comparable aggregate data on public finances are obtained from the Annual National Accounts harmonized by the $\mathrm{OECD}^{21}$ These database reports aggregate public revenues and public expenditures by broad category, as percentage of GDP. As for revenues, we distinguish between taxes based on income (including social contributions and taxes on personal and corporate income), taxes based on consumption (VAT and excise duties), and other taxes. As for expenditures, we distinguish between social protection expenditures, education expenditures, and government consumption. For the rest of the world, we average the fiscal data from Brazil, China, and India. Since our model rules out the possibility of a budgetary deficit or surplus, we rescale all items so that the total government budget is equal to the mean of the observed shares of public revenues and expenditures in GDP for the year 2010. Second, we use the Social Expenditure Database (SOCX) of the OECD to decompose social protection expenditures by program ${ }^{22}$ The SOCX database includes internationally comparable statistics on public social expenditures at the program level, as well as net social spending indicators. We extract data on expenditures linked to sickness and disability, pension benefits, family and children, unemployment and other transfers, as percentage of total social protection expenditures.

Finally, we disaggregate education expenditures and all social protection expenditures by education level, age group, and legal status (natives versus foreigners) using the European Union Statistics on Income and Living Conditions (EU-SILC) provided by Eurostat for European countries, and the fiscal profiles used in Chojnicki et al. (2011) for the United States. We extract personal characteristics (such as country of birth, year of birth, and highest level of education attained), data on social benefits (sickness benefits, disability benefits, survivor benefits, old-age benefits, unemployment benefits, and educationrelated allowances), and the sampling weight of each individual.

\footnotetext{
${ }^{21}$ See https://data.oecd.org/

${ }^{22}$ See https://data.oecd.org/socialexp/social-spending.htm
} 
We compute the amount of benefits received by the representative individual from the eight groups of residents distinguished in our model, and rescale each profile to match the aggregate level obtained from the SOCX database. The resulting profiles capture cross-country differences in the fiscal treatment of immigrants, their demand for social benefits (depending on age, age of arrival, education, fertility, intentions to return etc.), and their eligibility to welfare programs ${ }^{23}$ For Canada, and Australia, we use the US profiles. For other countries, we use the average OECD profiles, rescaled to match the aggregate public finance data of the country.

Table B4 in the Appendix B characterizes the fiscal policy of each OECD member state, as percentage of GDP. Column 1 gives the aggregate amount of fiscal revenues and expenditures under the balanced budget assumption. Columns 2 and 3 report the shares of income and consumption taxes in GDP (used to calibrate $t_{c}$ and $v_{c}$ ). Columns 6 to 9 give the structure of public expenditures. General public spending and education expenditures in columns 4 and 5 form the government consumption. To compute the $G_{a, c}^{m}$ profiles, we assume a constant amount of public spending per inhabitant and use the EU-SILC profiles to allocate education expenditures across the four groups of working-age adults. As for the $T_{a, c}^{m}$ profiles, we aggregate health, old-age, unemployment and family benefits, which are allocated across groups of individuals using the EU-SILC profiles. We also include the residual category in column 10, which combines residual transfers minus residual taxes. For these other net transfers, we assume a constant amount per inhabitant.

The last two columns illustrate the net fiscal contribution of working-age individuals (column 11) and immigrants (column 12) for the year 2010. In all countries, public intervention involves a fiscal redistribution from working-age individuals to retirees, which varies between 5.0 percent of GDP in New Zealand and 17.5 percent in Luxembourg (the OECD average equals 10.8 percent). The last column gives the fiscal impact of the total stock of immigrants in 2010. It is positive in 20 countries and negative in 14 countries, under the benchmark assumption that government consumption is proportional to population size. The fiscal impact varies between -1.2 percent of GDP in Chile to 5.0 percent in Switzerland (the OECD average equals 0.3 percent).

Common parameters - The model includes three common parameters, $\left\{\epsilon, \sigma_{S}, \sigma_{M}\right\}$. The elasticity of substitution between varieties of goods, $\epsilon$, is estimated in the range of 3 to 8.4 by Feenstra (1994). We take $\epsilon=4$ as a benchmark value. As far as elasticities of substitution between groups of worker are concerned $\left(\sigma_{S}\right.$ and $\left.\sigma_{M}\right)$, we follow Docquier et al. (2014) and use their intermediate value: $\sigma_{S}=1.75$ and $\sigma_{M}=20$. We consider alternative levels in the robustness analysis.

Other parameters - The model also includes other parameters that vary across countries or country pairs. These include $\left\{f_{c}, \theta_{c}^{S}, \theta_{c}^{M}, A_{c}\right\}_{c \in C}$, and bilateral trade costs $\left[\tau_{c j}\right]_{c, j \in C}$.

As for the fixed cost of entry, $f_{c}$, we use the Doing Business database and the World Development Indicators from the World Bank (2010). We construct a synthetic indicator using three proxies for the

\footnotetext{
${ }^{23}$ On the effect of age of arrival and (endogenous) return intentions, see $\operatorname{Kirdar}$ (2012).
} 
cost of entry: the number of days needed to fulfill the formal requirements to establish a firm, the cost of starting a business (as percentage of GDP per capita), and the share of new firms registered. For a given $f_{c}$, we have $\Delta B_{c} / B_{c}=\Delta \bar{L}_{c}^{T} / \bar{L}_{c}^{T}$ from eq. 21. The level of the entry cost is important for the rest of the calibration (it affects income per capita and prices), but has no influence on the price and wage responsiveness to migration shocks. Without loss of generality, we normalize our synthetic indicator by its minimum value, obtained for Norway, since the model considers homothetic preferences and production. The values obtained for the other countries vary in the range of 1 to 3.64. For the rest of the world, we computed a GDP-weighted sum of the 33 largest non-OECD countries. The firm preferences for each group of workers (i.e. $\theta_{c}^{S}, \theta_{c}^{M}$ ) are computed to match the data on income disparities by education level and origin. The data on the wage ratio between college graduates and the less educated are taken from Hendricks (2004), while the data on the wage ratio between immigrants and non-migrants come from Büchel and Frick (2005). Combining these sources with data on relative population shares, we compute the firms' preference parameters that match the actual labor income shares in each country. Finally, the TFP residuals, $A_{c}$, are calibrated to fit the levels of nominal GDP. Our macroeconomic data and country-specific parameters are provided in Table B5 in the Appendix B.

Wages and total factor productivity determine the unit cost of production, the price of domestic goods (from eq. (15p and eq. (18)), and the total expenditures, $X_{c}$. Hence, the matrix of bilateral costs, $\tau_{c j}$, can be calibrated to match the matrix of adjusted trade flows between countries (adjustments are needed to balance exports and imports) ${ }^{24}$ These calibrated trade costs are instrumental to spreading shocks across countries; we consider them as exogenous.

Validation - Our parametrization strategy consists in calibrating country-specific parameters and trade costs so as to perfectly match the observed demographic, fiscal and economic characteristics of countries and trade flows. We use all the degrees of freedom of the data to identify the parameters needed. Consequently, our model is exactly "identified" and cannot produce a test of its assumptions. In order to establish the relevance of our parametrization method, we examine whether our identified parameters exhibit realistic correlations with the related explanatory variables, or reasonable properties:

- Our estimates of the fiscal impact of immigration exhibit a correlation of 0.45 with the levels reported in Table 3.7 in OECD (2013), although the OECD does not impose a balanced budget and constant tax rates across individuals.

- In our model, the variable $B_{c}$ may be interpreted as an indicator of market size, and is highly correlated with the population level observed (correlation of 0.99).

- The TFP levels can be compared to the measures of labor efficiency $[25$ The cross-country correlation between the TFP variable $A_{c}$ and the actual data on labor productivity is equal to 0.72 . One

\footnotetext{
${ }^{24}$ The correlation between our predicted bilateral trade flows and the actual (unadjusted) data equals 0.99 . It is not equal to one because we adjust trade flows to balance exports and imports, and we constrain $\tau_{c j}$ to be larger than or equal to one.

${ }^{25} \mathrm{We}$ consider the GDP per hour worked from the OECD database.
} 
has to remember that the computed residual and TFP values incorporate more than just the level of technology or labor productivity. For instance, they may be affected by the quality of institutions, infrastructure, legislation, education, social capital, etc.

- The nominal wages predicted by the model are in line with the actual data. The composite wage rates $W_{c}$ are correlated with the cross-section average annual wages reported in the $O E C D$ database. The correlation is 0.85 .

- Finally, our bilateral trade costs, calibrated to match the bilateral trade flows, are well correlated with the traditional determinants of trade barriers. We have regressed our $\tau_{c j}$ on standard bilateral variables that affect the volume of exports, obtaining very similar results to those of Anderson and van Wincoop (2003), Silva and Tenreyro (2006), and other gravity-like analyses of international trade 26

\subsection{Benchmark results}

To quantify the impact of migration on welfare, we compare the observed utility levels, as defined in eq. (5), with counterfactual utility levels obtained when recent migrants were sent back to their home countries. For each type of worker, the change in utility is expressed as a percentage deviation from the non-migration counterfactual:

$$
\frac{\Delta U_{a, c}^{m}}{U_{a, c}^{m}}=\frac{\left(U_{a, c}^{m}\right)_{\text {Reference }}-\left(U_{a, c}^{m}\right)_{\text {Counterfactual }}}{\left(U_{a, c}^{m}\right)_{\text {Counterfactual }}} .
$$

Hence, a positive difference implies a welfare gain due to global migration, while a negative one implies a welfare loss.

In the benchmark analysis, the counterfactual consists in repatriating all the migrants that arrived to their destination countries between 2000 and 2010. There are three reasons to focus on recent migration flows, instead of stocks. First, recent migrants are less assimilated and are likely to exhibit a stronger complementarity to native workers on the labor market. On the contrary, the immigration stock includes old waves of better assimilated immigrants who are now in retirement or have gradually become closer substitutes to natives on the labor market (by way of comparison, we simulate the effect of repatriating the total stock of migrants in Section 3.3. Second, recent empirical studies on the interactions between immigrants and native workers are usually based on recent flows of workers (see Card, 2009, Docquier et al. 2014, Ottaviano and Peri, 2012). Finally, recent legal migrants are younger and more educated

\footnotetext{
${ }^{26}$ In our regression, the set of controls includes geographic distances between any two countries and dummies for common border, common language, colonial ties, and the existence of a free trade agreement. The data are taken from the CEPII gravity dataset. The estimates of our OLS regression are equal to 0.156 for distance, -0.324 for common border, -0.215 for common language, -0.258 for colonial ties, and -0.025 for free trade agreements. They are all significant at the 1 percent threshold and the $R^{2}$ equals 0.200 . Similar results are obtained when country-fixed effects are included.
} 
than older immigrants. Focusing on newer immigration enables us to shed light on the current patterns of global migration.

The benchmark results are depicted in Figure 2, Countries are sorted in descending order with respect to the average (or total) welfare effect. In Figure 1a, we first provide the average welfare impact of global migration for non-migrants, and its distribution by individual type (low-skilled workers, highskilled workers, and retirees). Figure $1 b$ then focuses on the average welfare impact and distinguishes between intra-OECD and extra-OECD migration flows. Finally, we apply the welfare decomposition method described in Section 2.5 to disentangle the welfare impact on college-educated and less educated workers (see Figures $2 \mathrm{a}$ and $2 \mathrm{~b}$ ).

Winners and losers from global migration - Figure $1 \mathrm{a}$ identifies the winners and losers from recent global migration flows. The average effect on non-migrants is positive in 28 OECD countries, nil in France, and negative in 5 traditional countries of emigration. The greatest gains are obtained in Spain (8.1 percent), Australia (7.9 percent), Canada (4.6 percent), Switzerland (4.6 percent), Ireland (4.4 percent), and New Zealand (4.3 percent). Welfare losses are obtained in Turkey ( -0.5 percent), Slovakia (-1.7 percent), Mexico (-1.8 percent), Estonia (-3.8 percent), and Poland (-3.8 percent). As stated above, we disregard remittances and overestimate the losses incurred in the latter countries. The magnitude of the average effect is highly correlated with the incidence of migration flows on population size (correlation of 0.91) and on the old-age dependency ratio (correlation of -0.89). On the contrary, it is poorly correlated with the migration-induced variation in the skill structure of the labor force (correlation of 0.20 with the change in the proportion of college-educated workers).

Within countries, the welfare effects are heterogeneous across types of individuals. They are positive for retirees in 31 countries (exceptions are Mexico, Estonia, and Poland). In our benchmark scenario, retirees do not work and only consume the transfers they receive from the government. They are only affected by the change in the ideal price index, which varies with the domestic market size and availability of additional varieties of foreign goods ${ }^{27}$ On the contrary, the effects on workers are also affected by fiscal and labor market effects (i.e. changes in income tax rates and wages). Global migration is beneficial for college-educated natives in 28 countries (the same countries as above), and for the less educated in 22 countries only. Overall, we identify many winners and a few losers. More precisely, there are seven countries combining average welfare gains and welfare losses for the less educated. These are countries where recent migration flows are not too large (excluding strong market-size effects), and where recent migration has reduced the proportion of college graduates in the labor force (Israel, Belgium, Korea, Chile, Japan, Germany, and Iceland). Nevertheless, with the exception of Iceland and Germany (-1.0 percent in utility), the welfare losses for the low-skilled are close to zero.

Moreover, our simulations indicate that recent global migration flows have increased the average

\footnotetext{
${ }^{27}$ This assumption will be relaxed in the robustness section, in which we consider a scenario with endogenous consumption tax rates.
} 
utility of non-migrants by 1.1 percent in the OECD (and by 0.8 percent if older cohorts of migrants are included in the average), and have decreased the average utility of those left behind by 0.3 percent in the rest of the world. Overall, a large majority of non-migrants in OECD countries have benefited from recent migration flows. With a few exceptions, the within-country effects are limited compared to the between-country ones. The correlation rates between the average and group-specific welfare impacts are equal to 0.81 for college-educated workers, 0.91 for less educated workers, and 0.98 for retirees.

Intra-OECD vs Extra-OECD - In Figure 1b, we focus on the average welfare effect of migration flows (i.e. between-country disparities) and distinguish between intra-OECD and extra-OECD migration flows. Extra-OECD migration basically consists of an inflow of immigrants from non-OECD countries. On the contrary, intra-OECD migration is a zero-sum game involving net immigration and net emigration countries. Another difference is that intra-OECD migrants are on average more educated than extraOECD migrants.

It comes out that the effect of extra-OECD migration is positive in 32 countries; the exceptions are Poland and Estonia (average welfare effects of -0.3 and -2.7 percent, respectively), two countries which send a substantial number of emigrants to Russia or other Eastern European destinations. As far as intraOECD migration is concerned, we identify 17 winners and 16 losers (the effect is nil in Sweden). The effect is negative in traditional emigration countries (Turkey, Slovakia, Hungary, Mexico, Estonia, and Poland), but also in Canada, New Zealand, Portugal, Belgium, Korea, Chile, Japan, Iceland, Germany, and France. Welfare losses are usually small; the largest effect is obtained in New Zealand (-1.2 percent), Iceland (-0.7 percent), and Belgium (-0.6 percent). The gains are larger and mostly concentrated in a few countries (3.7 percent in Switzerland, 2.0 percent in Spain, 1.9 percent in Ireland, 1.3 percent in Norway, and 1.2 percent in Australia and Austria).

Overall, extra-OECD migration flows increase the average utility of non-migrants by 1.2 percent in the OECD (and by 0.9 percent if older cohorts of migrants are included in the average), and decrease the utility of those left behind by 0.3 percent in the rest of the world. Intra-OECD migration flows decrease the average utility of non-migrants by 0.1 percent in the OECD. Hence, the bulk of welfare gains from global migration is driven by extra-OECD migration, in line with Di Giovanni et al. (2015) or Iranzo and Peri (2009). As stated above, extra-OECD immigration is usually perceived in opinion poll surveys as a massive inflow of uneducated people trying to gain access to the labor markets and welfare systems of rich countries; intra-OECD migration is less frequently seen as problematic. As far as the economic effects are concerned, popular perceptions are clearly at odds with the predictions of our model.

Transmission channels - In Figures $2 \mathrm{a}$ and $2 \mathrm{~b}$, we disentangle the welfare impact on college graduates and less educated non-migrants using the decomposition method explained in Section 2.5. The residual general equilibrium effects are not reported here. Many studies conducted on the United States or on a few European countries have demonstrated that the labor market and fiscal effects of migration are relatively small. Our simulations show that these effects can be much larger in other countries. 

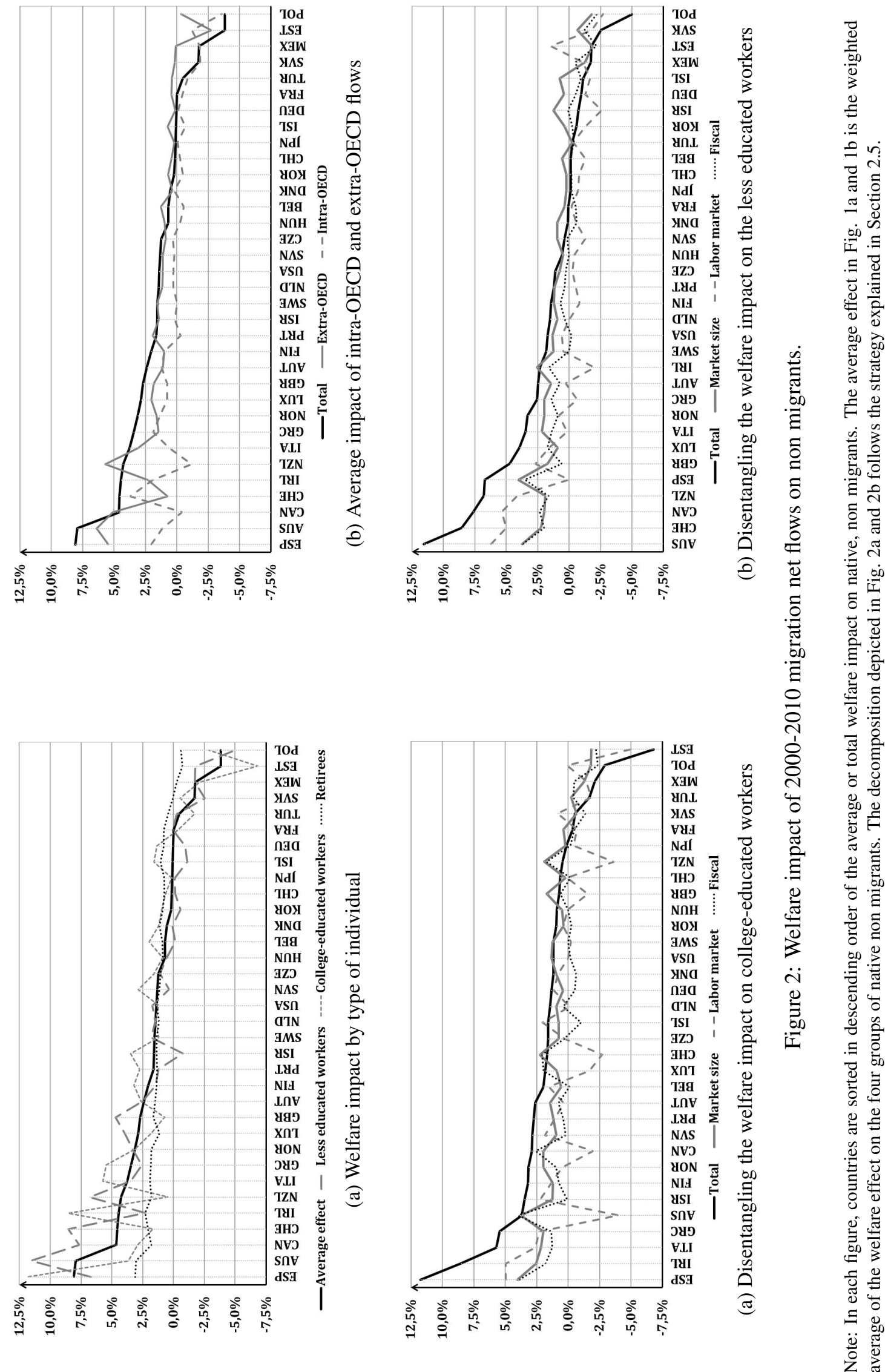
The standard deviation in the market-size effect equals .013, to be compared with .022 and .014 for the labor market and fiscal effects, respectively. The labor market and fiscal channels are important sources of heterogeneity across countries. However, the market-size effect is the main source of welfare gains. Our simulations reveal that, on average, it increases the welfare of all workers by 1.0 percent in the OECD. This is greater than the average fiscal effect ( 0.4 percent) and the average labor market effects ( 0.2 percent for college graduates and 0.1 percent for the less educated) ${ }^{28}$ In addition, the correlation between the market-size and total effects is large ( 0.85 for college-educated workers and 0.84 for the less educated).

Overall, focusing on the 28 countries where global migration has improved the welfare of college graduates, the market-size effect is dominant in 14 cases (to be compared with 11 cases for the labor market effect, and only 3 cases for the fiscal effect). Similarly, focusing on the 22 countries where global migration has improved the welfare of the less educated, the market-size effect is dominant in 16 cases (to be compared with 5 cases for the labor market effect, and 1 case for the fiscal effect). As the market-size effect affects the utility of all the residents of a given country identically, we conclude that the between-country consequences of global migration exceed the within-country ones. The market-size and love-of-variety mechanisms have been largely disregarded in the literature on the welfare consequences of migration (exceptions are Di Giovanni et al., 2015, Iranzo and Peri, 2009). Our results suggest that market size is an important missing ingredient in the existing literature.

\subsection{Robustness checks}

In this section, we conduct three types of robustness checks. First, we assess the robustness of our results to three mechanisms included or not in our model. We simulate the model without trade flows, with schooling externalities, or under alternative fiscal rules. Second, we analyze the sensitivity of our results to the choice of two important elasticities: the elasticity of substitution between goods in the utility function (governing the preference for variety), and the elasticity of substitution between native and immigrant workers in the production function (governing complementarities on the labor market). Figure 4 depicts the results of these two sets of robustness checks. Third, we simulate the welfare effect of a repatriation of the total stock of migrants (instead of recent migration flows) to their home country. The results of the stock simulation are depicted in Figure 6

The role of trade - International trade is a channel through which the market-size effect is propagated across countries. A change in the mass of varieties in one country (due to a migration shock) affects the mass of varieties available in all of its trade partners, ceteris paribus. Hence, international trade is likely to mitigate the redistributive effects of global migration. To control for the role of international trade in propagating the gains from migration, we conduct the same counterfactual simulations assuming a closed-economy framework. We set all the pair-specific trade costs to infinity $\left(\tau_{c j}=\infty \forall c \neq j\right.$ ),

\footnotetext{
${ }^{28}$ On average, the residual general equilibrium effect equals 0.2 percent.
} 
such that the bilateral trade flows are zeroed before the shock $\left(X_{c j}=0 \forall c \neq j\right)$. Then, we simulate the effects of the repatriation counterfactual.

Figure 3a compares the welfare changes under autarky with those in the benchmark. We notice that the welfare effects with and without trade are almost identical. This is because our model has a single production sector, which aggregates the tradable and non-tradable sectors. Therefore, our calibrated trade costs are rather high. Distinguishing between a tradable and a non-tradable sector could increase the differences between the two scenarios (i.e. with and without trade) if market-size effects are larger in the tradable sector (i.e. if product differentiation is more important in the tradable sector). Moreover, in the absence of trade, both welfare gains in the most attractive countries and welfare losses in emigration countries are greater. Hence, existing trade flows slightly smooth the welfare impact of global migration.

Schooling externalities - Our benchmark model assumes exogenous levels of TFP. However, recent evidence of a schooling externality on TFP has been identified at the country level (e.g. Benhabib and Spiegel, 2005, Vandenbussche et al., 2006), or at the metropolitan level (Acemoglu and Angrist, 2000, Ciccone and Peri, 2006, Iranzo and Peri, 2009, Moretti, 2004a|b). We thus simulate a variant of our model in which the economy-wide TFP level, $A_{c}$, is a concave function of the average proportion of high-skilled workers in the economy, $\kappa_{c}$ :

$$
A_{c}=\bar{A}_{c} \kappa_{c}^{\lambda}, \quad \text { with } \quad \kappa_{c} \equiv \frac{L_{w, c}^{H}+L_{w, c}^{h}}{L_{w, c}^{T}}
$$

where $\lambda$ is the elasticity of $A_{c}$ with respect to $\kappa_{c}$, and $\bar{A}_{c}$ is an exogenous scale factor. As in De la Croix and Docquier (2012), we use $\lambda=0.3$. This roughly corresponds to the average elasticity of $A_{c}$ to $\kappa_{c}$ in a simple cross-country OLS regression.

The results are presented in Figure 3a. Not surprisingly, schooling externalities change the magnitude of the effect in countries where global migration affects human capital. The gains are greater in countries such as Australia, Canada, Switzerland, and New Zealand, while the losses are more important in Belgium, Iceland, Germany, Israel, or Slovakia.

Assessment of the fiscal impact - In our benchmark simulation, the average fiscal impact amounts to 0.4 percent: it is smaller than the average market-size effect, but greater than the labor market effect. To assess the robustness of our results to the fiscal rule and to the calibration of the fiscal bloc, we consider three variants of fiscal policy. First, we assume that the income tax rate is constant and that the consumption tax rate adjusts to balance the government budget (see eq. (23)). Under this variant, labeled as "VAT adjusted", retirees are affected by the fiscal adjustment. Second, we assume that all public consumption expenditures (except education) are constant. Under this variant, labeled as "Less congestion", homothetic changes in population size induce variations in the tax rate. Finally, we introduce an exogenous income tax gap, $t_{c}^{g}$, between immigrants and natives (i.e. $t_{c}^{m i g}=t_{c}^{\text {nat }}+t_{c}^{g a p}$ ) and calibrate it so that our initial equilibrium in 2010 perfectly fits the estimated fiscal impact of immigration 
provided in Table 3.7 in OECD (2013). As stated above, in the benchmark, the correlation rate between our estimated fiscal impact of immigration and the OECD estimates was equal to 0.45 . This variant is labeled as "As OECD". The results are depicted in Figure 3b. They are strongly robust to the choice of the fiscal rule and to the calibration of the initial fiscal impact of immigration, however they are more sensitive to the relationship between the amount of public spending and the population size. Not surprisingly, welfare gains are larger when a fraction of public spending is not affected by immigration. On the contrary, welfare losses are greater in net emigration countries under this scenario.

Sensitivity to parameters - We now investigate the sensitivity of our results with respect to the calibration of the parameters. In Figure 4a, we let $\epsilon$, the elasticity of substitution between varieties in eq. (1), vary between 3 and 7 (the benchmark value equals 4). This virtually covers the range of values provided in Feenstra (1994). In Figure 4b, we let $\sigma_{M}$, the elasticity of substitution between native and immigrant workers in eq. $8 \mathrm{a}, 8 \mathrm{~b}$, , vary between 15 and 25 (the benchmark value equals 20).

Even though a higher (lower) value of $\epsilon$ weakens (strengthens) the sensitivity of price indexes to shocks in the mass of varieties (which directly influences the magnitude of the market-size effect), our results are extremely robust to changes in $\epsilon$. As far as labor complementarities are concerned, greater effects are identified when $\sigma_{M}$ is smaller. The lower the substitution between different labor types, the stronger the reaction of efficient labor composites to the changes in supplies of workers, and the more dispersed the welfare effects of these shocks.

Global migration stocks - Finally, we consider a last counterfactual, which consists in repatriating the total stock of migrants (whatever their year of entry) to their source countries. This allows us to assess whether the negative opinions about immigration and emigration reported in opinion polls could be motivated by adverse effects of older waves of migration. The results of the stock simulation are depicted in Figure 6, which follows exactly the same structure as Figure 2.

Figure $5 \mathrm{a}$ identifies the winners and losers from global migration stocks ${ }^{29}$ The average welfare impact is positive in 24 OECD countries (against 28 for the flow simulation) and its magnitude is usually greater than in the benchmark. The largest gains are obtained in Luxembourg, Australia, Canada, Switzerland, and Ireland. Welfare losses are obtained in Poland, Mexico, Slovakia, and Turkey, but also in richer countries such as Iceland, Korea, France, and Portugal. The magnitude of the average effect is highly correlated with the incidence of migration flows on population size (correlation of 0.77 ) and on the old-age dependency ratio (correlation of -0.32).

The welfare effects are heterogeneous across types of individuals. They are positive for retirees in 33 countries (the only exception is Mexico). Global migration is beneficial for college-educated natives in 22 countries, and for the less educated in 27 countries. Welfare losses are small, except in traditional emigration countries (including Portugal), but as stated above, we do not account for remittances.

\footnotetext{
${ }^{29}$ Figure $\mathrm{B} 2$ in the Appendix $\mathrm{B}$ compares the average welfare impact of migration stocks and migration flows. The correlation rate between these effects is equal to 0.71 .
} 

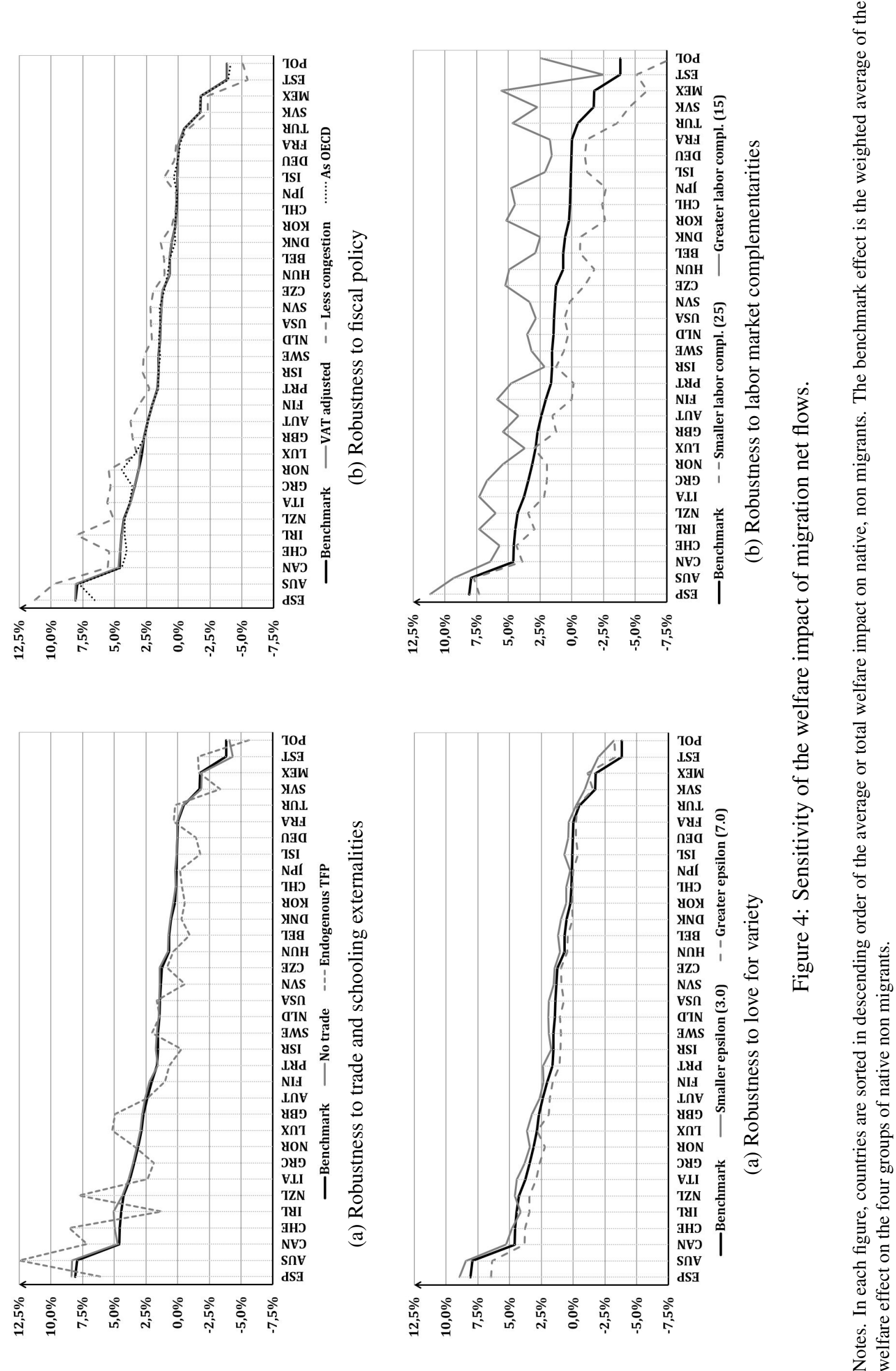

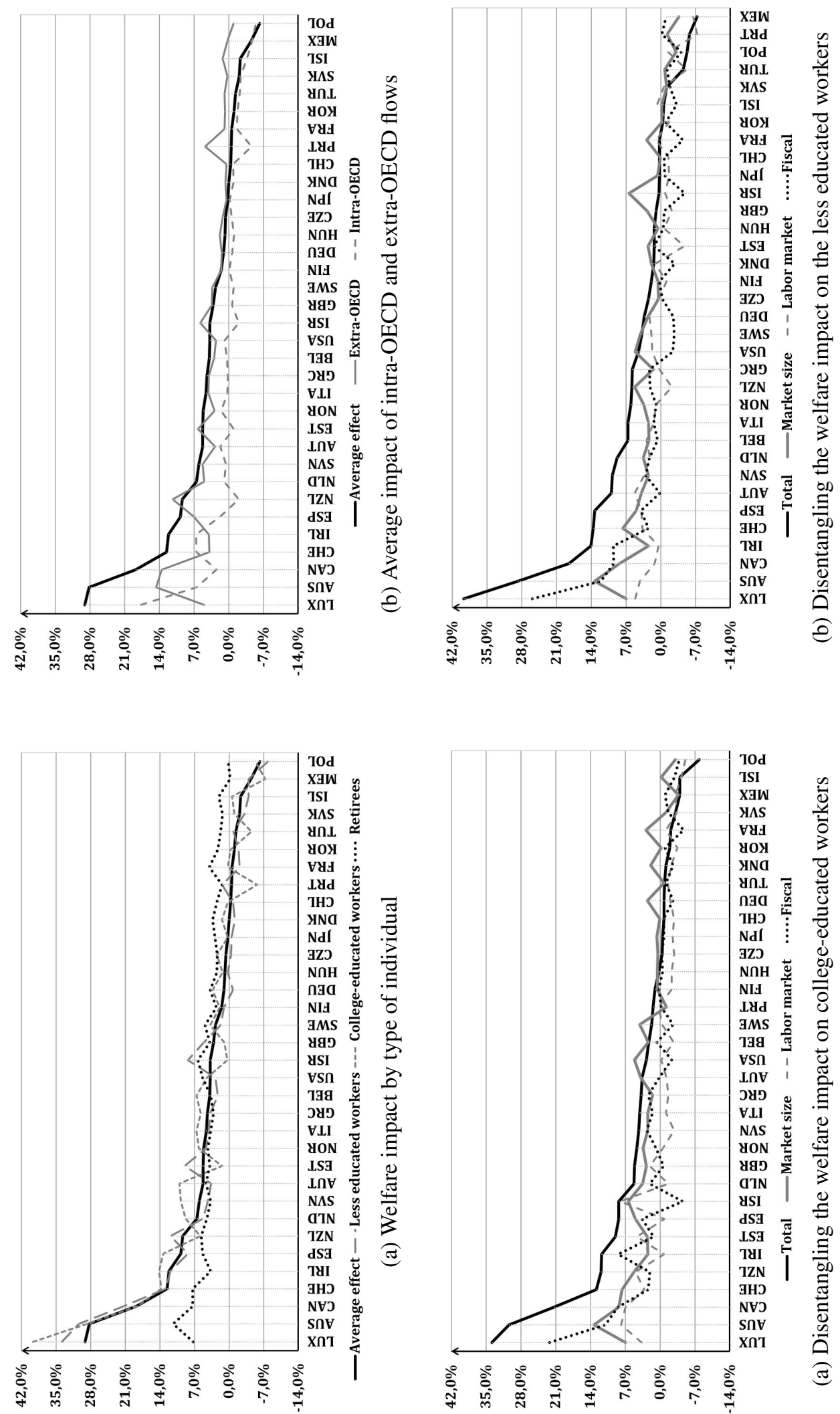
The correlation rates between the average and group-specific welfare impacts are equal to 0.96 for college-educated workers, 0.98 for less educated workers, and 0.87 for retirees. This confirms that with a few exceptions, within-country effects are limited compared to between-country effects.

Figure $5 \mathrm{~b}$ distinguishes between intra-OECD and extra-OECD migration flows. As in the benchmark, extra-OECD migration increases the average welfare of non-migrants in 33 countries (the exception is Poland), whereas intra-OECD migration induces 14 winners and 20 losers. Overall, extra-OECD migration stocks increase the average utility of non-migrants by 2.4 percent in the OECD, and decrease the utility of those left behind by 1.7 percent in the rest of the world. Intra-OECD migration stocks decrease the average utility of non-migrants by 0.6 percent in the OECD. Again, the bulk of welfare gains from global migration are driven by extra-OECD migration.

Figures $6 \mathrm{a}$ and $6 \mathrm{~b}$ disentangle the welfare impact on college graduates and less educated citizens using the decomposition method explained in Section 2.5. For the stock simulation, the standard deviation in the market-size effect equals 0.034 . For college graduates, standard deviations in fiscal and labor market effects equal 0.050 and 0.034 ; and for the less educated, they equal 0.057 and 0.030 , respectively. However, the market size remains the main source of welfare gains. On average, it increases the welfare of all workers by 2.6 percent in the OECD. This is greater than the average fiscal effect ( +1.2 percent) and the average labor market effect ( 0.2 percent for the less educated and -0.4 percent for college graduates). The correlation between the market-size and total effects is large ( 0.84 for college-educated workers and 0.79 for the less educated). Overall, focusing on the 22 countries where global migration has improved the welfare of college graduates, the market-size effect is the dominant effect in 14 cases. Similarly, focusing on the 27 countries where global migration has improved the welfare of the less educated, the market-size effect is the dominant effect in 20 cases. This confirms that the market size is instrumental to explaining the welfare consequences of migration.

\section{Conclusion}

The current economic and demographic situation faced by many OECD countries has kindled debates over the economic impact of migration. Natives in developed countries predominantly see immigration as a source of adverse economic effects, not as a stimulus for greater competitiveness and welfare gains. This is especially the case for immigration flows from less developed countries. The academic literature has not confirmed these presumptions. Isolated studies of the labor market and fiscal impacts of migration have shown that the economic effects are rather small and presumably positive in many countries. However, with a few exceptions, the existing literature has imperfectly captured the complex interactions between the economic mechanisms through which global migration affects the welfare of non-migrants.

To assess the welfare impact of the current state of global migration (i.e. immigration of foreigners and emigration of natives) on OECD citizens, we develop a multi-country model that combines three economic transmission channels of migration shocks: the labor market effect, the fiscal effect, and the 
market-size effect. Borrowed from the trade literature, the latter arises from the relationship between the size of the aggregate demand (influenced by population movements) and the variety of goods available to consumers in a monopolistic environment with fixed entry costs.

Our integrated, open-economy model enables us to account for the interactions between these channels, as well as for the interdependencies between countries. It can be calibrated to perfectly fit the economic and demographic characteristics of the 34 OECD countries and the rest of the world, and the trade flows between them in the year 2010. We use the model to evaluate the utility level of non-migrant OECD citizens under the current allocation of the world population, and under a counterfactual allocation with no recent migration (as if the last decadal wave of migration had been nil). We show that recent global migration flows induced many winners and a few losers among OECD citizens. The group of winners represents 69.1 percent of the OECD non-migrant population aged 25 and over; this percentage increases to 83.0 percent if one only considers the 22 countries whose GDP per capita was above USD 30,000 in the year 2010. Although labor market and fiscal effects are non negligible in some countries, the greatest source of welfare gains comes from the market-size effect. It follows that the betweencountry consequences of global migration exceed the within-country ones. Welfare gains are obtained for virtually all citizens in traditional immigration countries. Welfare losses are essentially due to the (intra-OECD) emigration of a country's nationals. Using the estimated elasticities from the empirical literature, we find that the market size is instrumental in explaining the welfare consequences of migration. It is an important missing ingredient in the majority of studies on the welfare consequences of migration. Still our model with homogeneous preferences and competitive labor market structures leaves out a discussion of the employment effects of international migration. Accounting for labor market rigidities and origin-specific determinants of labor participation rates could help us refining the magnitude of the labor market, market size and fiscal impact of migration. We leave these challenging issues for further research.

\section{References}

Acemoglu, D. and Angrist, J. (2000). How large are human-capital externalities? Evidence from compulsory-schooling laws. pages 9-74.

Alesina, A., Harnoss, J., and Rapoport, H. (2013). Birthplace diversity and economic prosperity.

Anderson, J. E. and van Wincoop, E. (2003). Gravity with gravitas: A solution to the border puzzle. American Economic Review, 93(1):170-192.

Angrist, J. D. and Kugler, A. D. (2003). Protective or counter-productive? labour market institutions and the effect of immigration on eu natives. The Economic Journal, 113(488):F302-F331.

Arslan, C., Dumont, J.-C., Kone, Z., Moullan, Y., Özden, Ç., Parsons, C., and Xenogiani, T. (2015). A new profile of migrants in the aftermath of the recent economic crisis. 
Artuc, E., Docquier, F., Özden, Ç., and Parsons, C. (2015). A global assessment of human capital mobility: the role of non-OECD destinations. World Development, 65:6-26.

Aydemir, A. and Kirdar, M. G. (2013). Quasi-experimental impact estimates of immigrant labor supply shocks: the role of treatment and comparison group matching and relative skill composition. IZA Discussion Paper.

Barro, R. J. and Lee, J. W. (2013). A new data set of educational attainment in the world, 1950-2010. Journal of Development Economics, 104:184-198.

Battisti, M., Felbermayr, G., Peri, G., and Poutvaara, P. (2014). Immigration, search, and redistribution: A quantitative assessment of native welfare.

Benhabib, J. and Spiegel, M. M. (2005). Human capital and technology diffusion. Handbook of economic growth, 1:935-966.

Borjas, G. J. (2015). Immigration and globalization: A review essay. Journal of Economic Literature.

Broda, C. and Weinstein, D. E. (2006). Globalization and the gains from variety. The Quarterly Journal of Economics, 121(2):541-585.

Büchel, F. and Frick, J. R. (2005). Immigrants economic performance across Europe-does immigration policy matter? Population Research and Policy Review, 24(2):175-212.

Card, D. (2009). Immigration and inequality.

Chojnicki, X. (2013). The fiscal impact of immigration in france: a generational accounting approach. The World Economy, 36(8):1065-1090.

Chojnicki, X., Docquier, F., and Ragot, L. (2011). Should the us have locked heaven's door? Journal of Population Economics, 24(1):317-359.

Ciccone, A. and Peri, G. (2006). Identifying human-capital externalities: Theory with applications. The Review of Economic Studies, 73(2):381-412.

Collier, P. (2013). Exodus: How migration is changing our world. Oxford University Press.

De la Croix, D. and Docquier, F. (2012). Do brain drain and poverty result from coordination failures? Journal of Economic Growth, 17(1):1-26.

Di Giovanni, J. and Levchenko, A. A. (2013). Firm entry, trade, and welfare in zipf's world. Journal of International Economics, 89(2):283-296.

Di Giovanni, J., Levchenko, A. A., and Ortega, F. (2015). A global view of cross-border migration. Journal of the European Economic Association, 13(1):168-202.

Docquier, F., Özden, Ç., and Peri, G. (2014). The labour market effects of immigration and emigration in oecd countries. The Economic Journal, 124(579):1106-1145.

Dustmann, C. and Frattini, T. (2014). The fiscal effects of immigration to the uk. The Economic Journal, 124(580):F593-F643.

Dustmann, C., Frattini, T., Halls, C., et al. (2010). Assessing the fiscal costs and benefits of A8 migration to the uk. Fiscal Studies, 31(1):1-41. 
Evers, M., De Mooij, R., and Van Vuuren, D. (2008). The wage elasticity of labour supply: a synthesis of empirical estimates. De Economist, 156(1):25-43.

Feenstra, R. C. (1994). New product varieties and the measurement of international prices. The American Economic Review, pages 157-177.

Glitz, A. (2012). The labor market impact of immigration: A quasi-experiment exploiting immigrant location rules in germany. Journal of Labor Economics, 30(1):175-213.

Helpman, E., Melitz, M., and Rubinstein, Y. (2008). Estimating trade flows: Trading partners and trading volumes. The Quarterly Journal of Economics, 123(2):441-487.

Hendricks, L. (2004). Why does educational attainment differ across US states?

Iranzo, S. and Peri, G. (2009). Migration and trade: Theory with an application to the eastern-western european integration. Journal of International Economics, 79(1):1-19.

Kirdar, M. G. (2012). Estimating the impact of immigrants on the host country social security system when return migration is an endogenous choice. International Economic Review, 53(2):453-486.

Kraler, A. and Rogoz, M. (2011). Irregular migration in the european union since the turn of the millennium-development, economic background and discourses. Clandestino Project, Database on Irregular Migration.

Krugman, P. (1980). Scale economies, product differentiation, and the pattern of trade. The American Economic Review, pages 950-959.

Manacorda, M., Manning, A., and Wadsworth, J. (2012). The impact of immigration on the structure of wages: Theory and evidence from britain. Journal of the European Economic Association, 10(1):120151.

Melitz, M. J. (2003). The impact of trade on intra-industry reallocations and aggregate industry productivity. Econometrica, 71(6):1695-1725.

Moretti, E. (2004a). Estimating the social return to higher education: evidence from longitudinal and repeated cross-sectional data. Journal of Econometrics, 121(1):175-212.

Moretti, E. (2004b). Workers' education, spillovers, and productivity: evidence from plant-level production functions. American Economic Review, pages 656-690.

OECD (2013). The fiscal impact of immigration in oecd countries. International Migration Outlook 2013.

OECD (2015). Indicators of immigrant integration 2015: Settling in.

Ottaviano, G. I. and Peri, G. (2012). Rethinking the effect of immigration on wages. Journal of the European Economic Association, 10(1):152-197.

Özden, Ç., Parsons, C. R., Schiff, M., and Walmsley, T. L. (2011). Where on earth is everybody? the evolution of global bilateral migration 1960-2000. The World Bank Economic Review, 25(1):12-56.

Peri, G., Shih, K., and Sparber, C. (2013). Stem workers, H1B visas and productivity in us cities. London: Norface Migration. 
Silva, J. S. and Tenreyro, S. (2006). The log of gravity. The Review of Economics and Statistics, 88(4):641-658.

Storesletten, K. (2000). Sustaining fiscal policy through immigration. Journal of Political Economy, 108(2):300-323.

Vandenbussche, J., Aghion, P., and Meghir, C. (2006). Growth, distance to frontier and composition of human capital. Journal of Economic Growth, 11(2):97-127. 


\section{Appendices}

\section{Appendix A Stylized facts 1960-2010}

Concerns about migration have been correlated with the evolution of the magnitude of migration flows. Some stylized facts are provided in Figure A2. On the one hand, the average share of immigrants in the population of OECD economies increased from 4.4 in 1960 to 9.5 percent in 2010 (see the bold line in Fig. A1a). In particular, the average share of immigrants originating from developing countries increased from 1.4 to 5.6 percent 30 By the year 2010, the proportion of foreigners in the population exceeded 10 percent in 21 countries, and was above 20 percent in 5 countries (Australia, Canada, Luxembourg, New Zealand, and Switzerland). On the other hand, the evolution of emigration has been less spectacular in OECD countries. On average, the ratio of the stock of emigrants to the population only increased from 3.0 to 3.9 percent between 1960 and 2010 (see the bold line in Fig. A1b). However, disparities across countries are important. By the year 2010, five OECD member states exhibited emigration rates above 10 percent (Ireland, Luxembourg, Mexico, New Zealand, and Portugal) and 12 others exhibited rates above 5 percent. In most cases, emigrants are much more educated than those left behind, as shown in Artuc et al. (2015).

Such migration movements have a strong incidence on the socio-demographic characteristics of the 34 OECD member states. In Fig. A2a, we focus on net migration flows (entries minus exits) observed between 2000 and 2010, and compute the effect of these flows on three variables of interest, the size of the population aged 25 and over, the old-age dependency ratio (i.e. ratio of the population aged $65+$ over the population aged 25-64), and the proportion of college graduates in the population aged 25-64. The effect of migration flows on population size is positive in 29 cases and negative in 5 cases only (it varies between -7.5 percent in Estonia and 12.5 percent in Spain). It is negatively correlated with the effect on the dependency ratio, which varies between -4.5 percent in Spain and 2.8 percent in Estonia. As far as human capital is concerned, the effects are very heterogeneous. Recent migration flows increased the proportion of college graduates in six immigration countries (Australia, Canada, Luxembourg, New Zealand, Switzerland, and the United Kingdom) and Estonia (due to low-skilled emigration flows). It decreased human capital in 14 countries (Spain, Ireland, Italy, Greece, Israel, Finland, Slovenia, Iceland, Denmark, Belgium, Germany, Korea, Slovakia, and Poland), and induced negligible effects in the 13 other cases. Figure A2b illustrates the effect of total migration stocks on the same variables of interest. With a few exceptions, the effects on old-age dependency and human capital are similar to those of migration flows. On the contrary, the effect on the size of the population aged 25 and over is much larger (it varies between -13.9 percent in Mexico to 45.1 percent in Australia).

By changing the size and structure of the population, immigration and emigration are sources of welfare costs and benefits for non-movers. Through the structure of the labor force, migration flows affect the relative wages of high-skilled and low-skilled workers, as well as the income gap between natives and older migrants. Through changes in the age and education structures of the population, they affect the number of net contributors to (and net beneficiaries from) the welfare state and other public interventions. Labor mobility also affects the geographic distribution of workers and the aggregate demand for domestic goods and services, which alters the number of entrepreneurs and products available for consumption in all countries. Skill-biased migration can also influence the speed of knowledge accumulation and innovation, governing the evolution of total factor productivity (TFP). The welfare impact of global migration results from the complex interactions between these effects.

\footnotetext{
${ }^{30}$ More pronounced changes were observed in the richest OECD member states whose GDP per capita was above USD 30,000 in the year 2010 .
} 

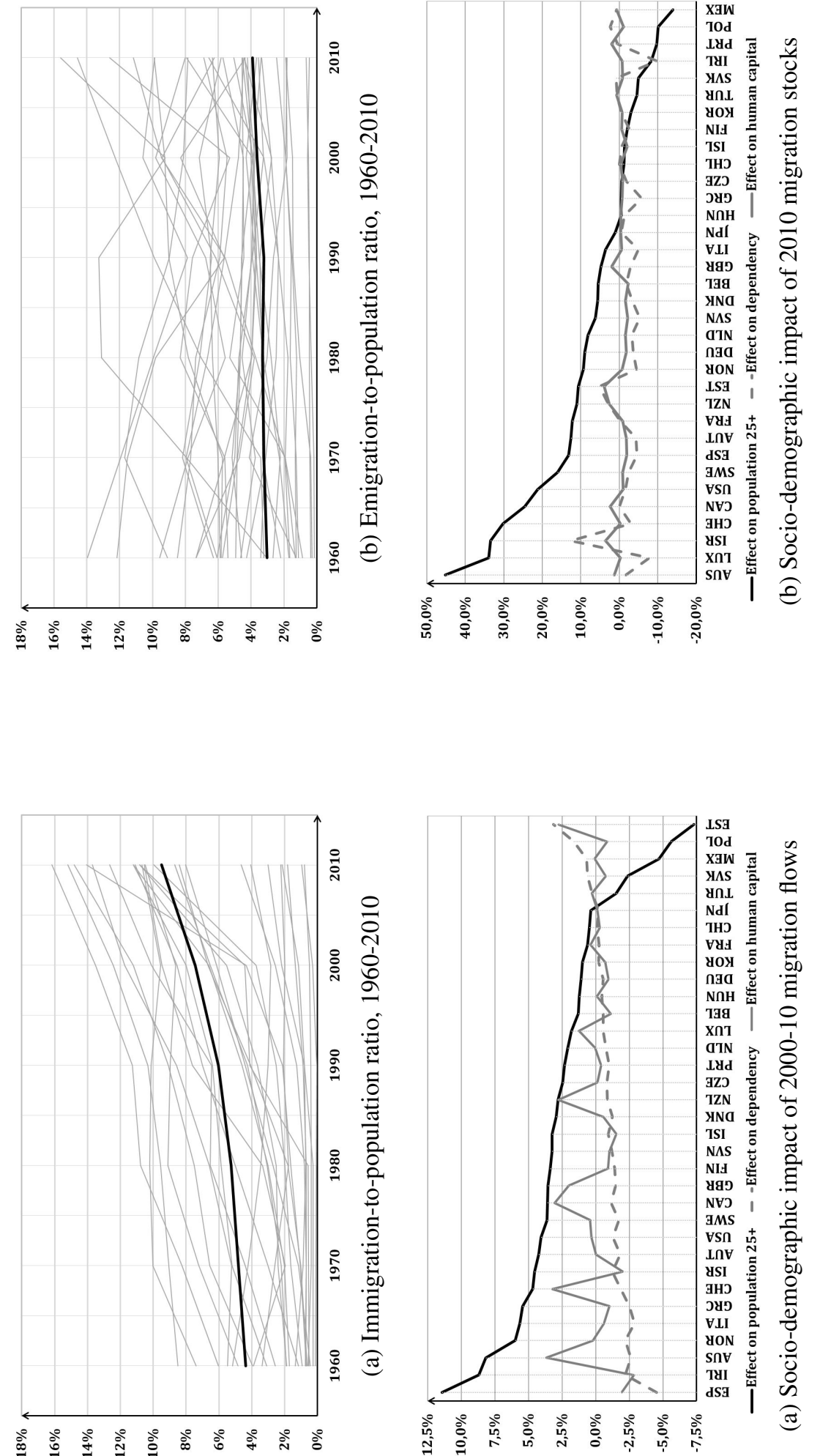

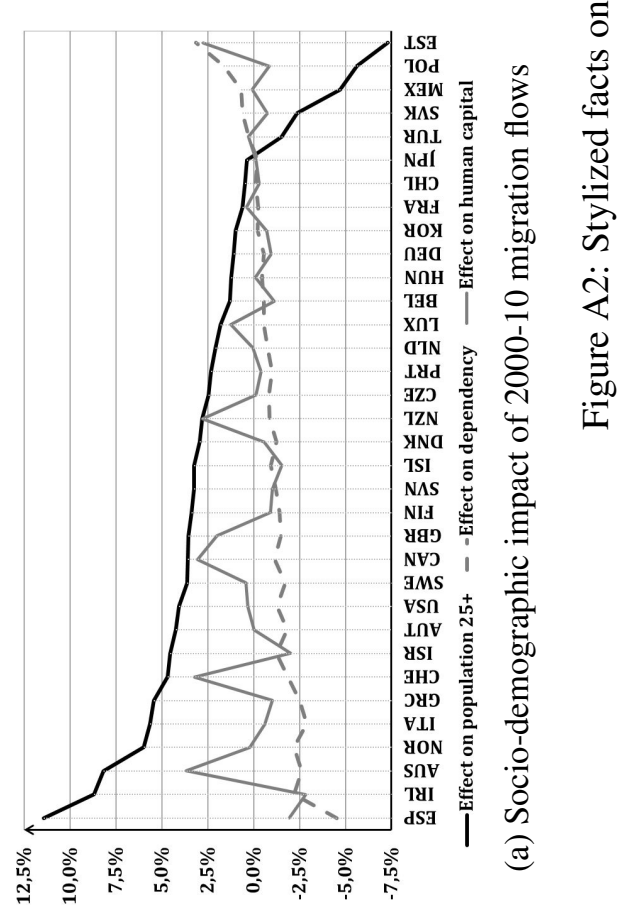

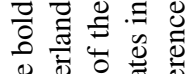

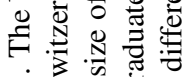

可记

กิ

可施

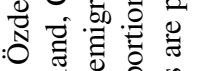

نั ङू

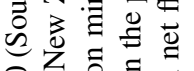

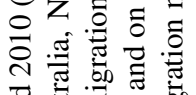

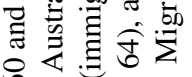

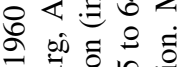

ธี

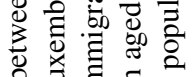

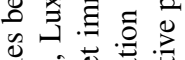

过氖密

言递宫

它芯苋

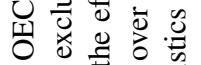

० 30.

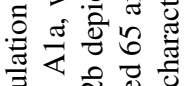

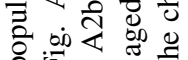

记氥.

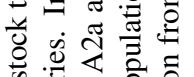

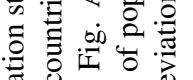

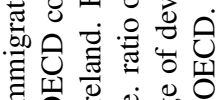

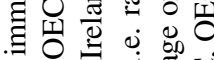

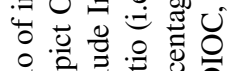

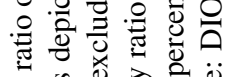

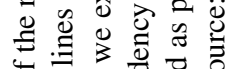

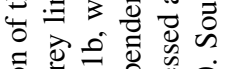

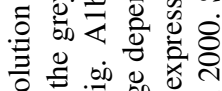

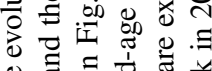

ป $\Xi$ 它就

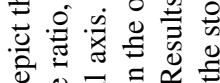

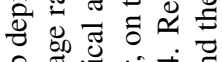

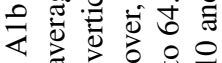

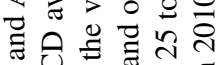

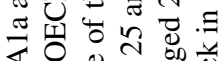
को

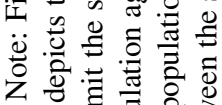

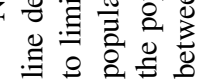




\section{Appendix B Data appendix}

Tables:

- B1. Population size and structure in 2010 in the OECD member states

- B2 Effect of migration stocks on the population structure

- B3. Effect of 2000-10 migration net flows on the population structure

- B4, Fiscal policy in the OECD member states

- B5. Macroeconomic data and calibrated, country-specific parameters

Figures:

- B1: Socio-demographic impact of 2010 migration stocks (X-axis) and 2000-10 migration flows (Y-Axis) as percentage of deviation from the no-migration counterfactual

- B2. Average welfare impact of 2010 migration stocks (X-axis) vs 2000-10 migration flows (YAxis) as percentage of deviation from the no-migration 


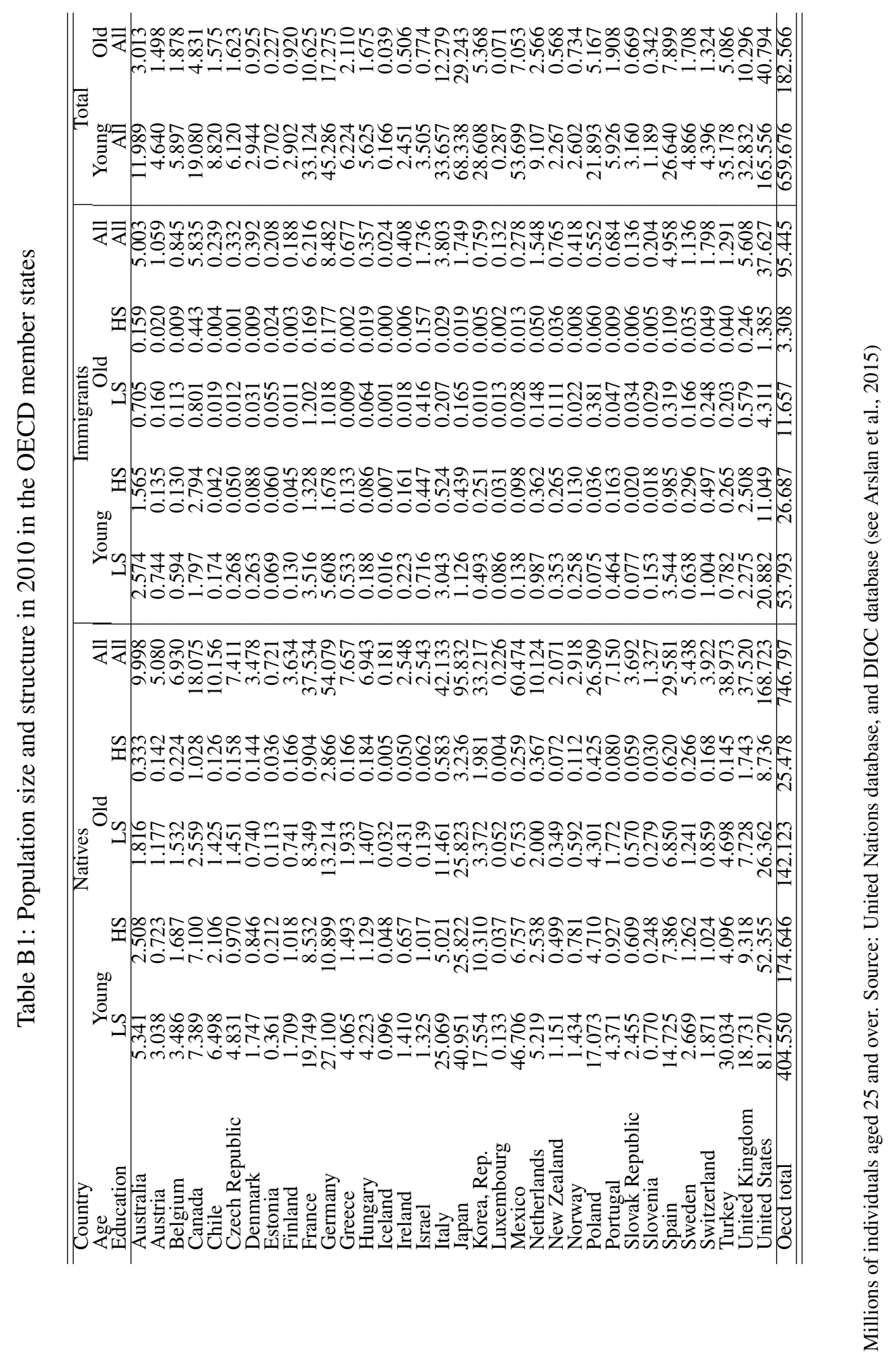




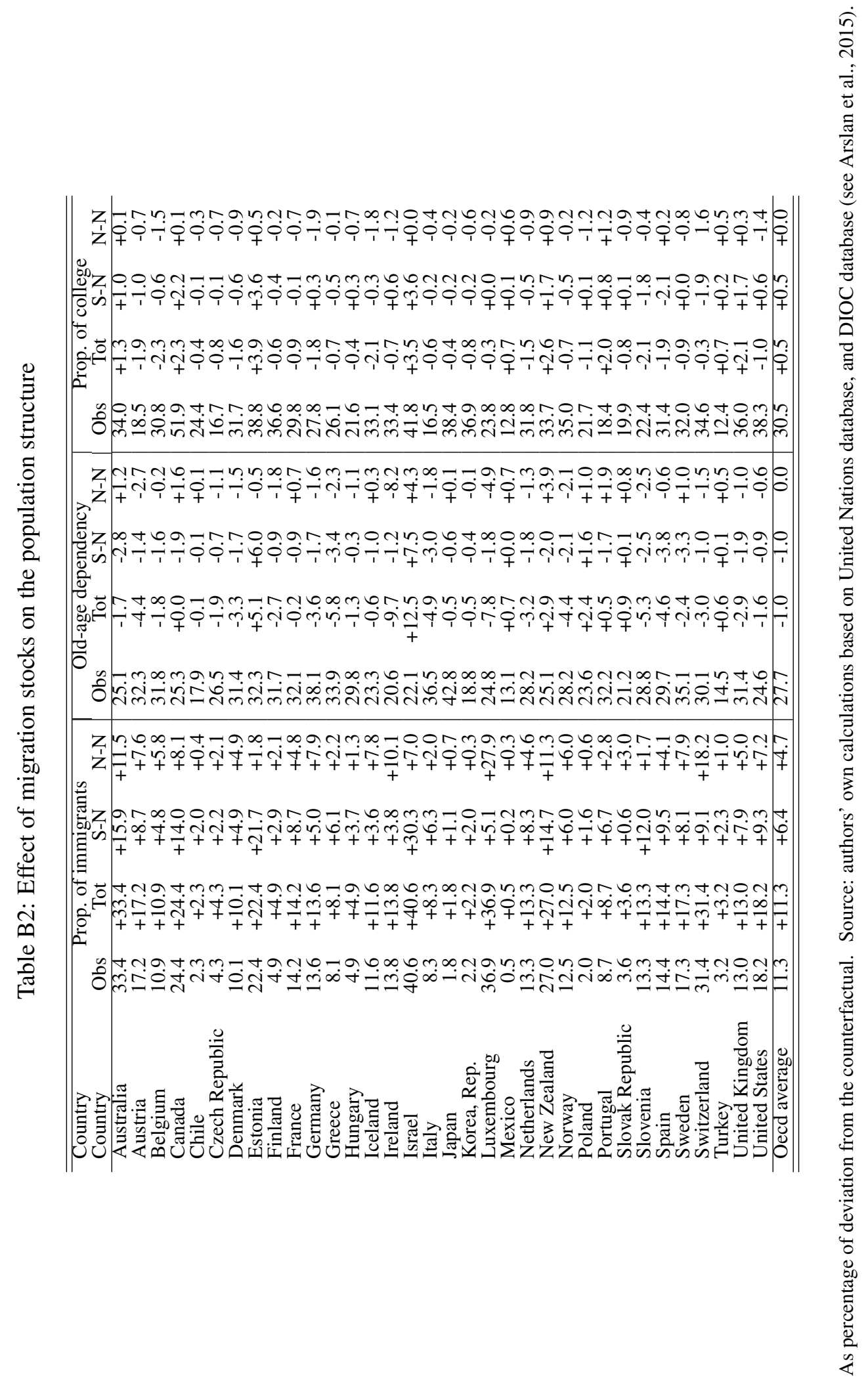




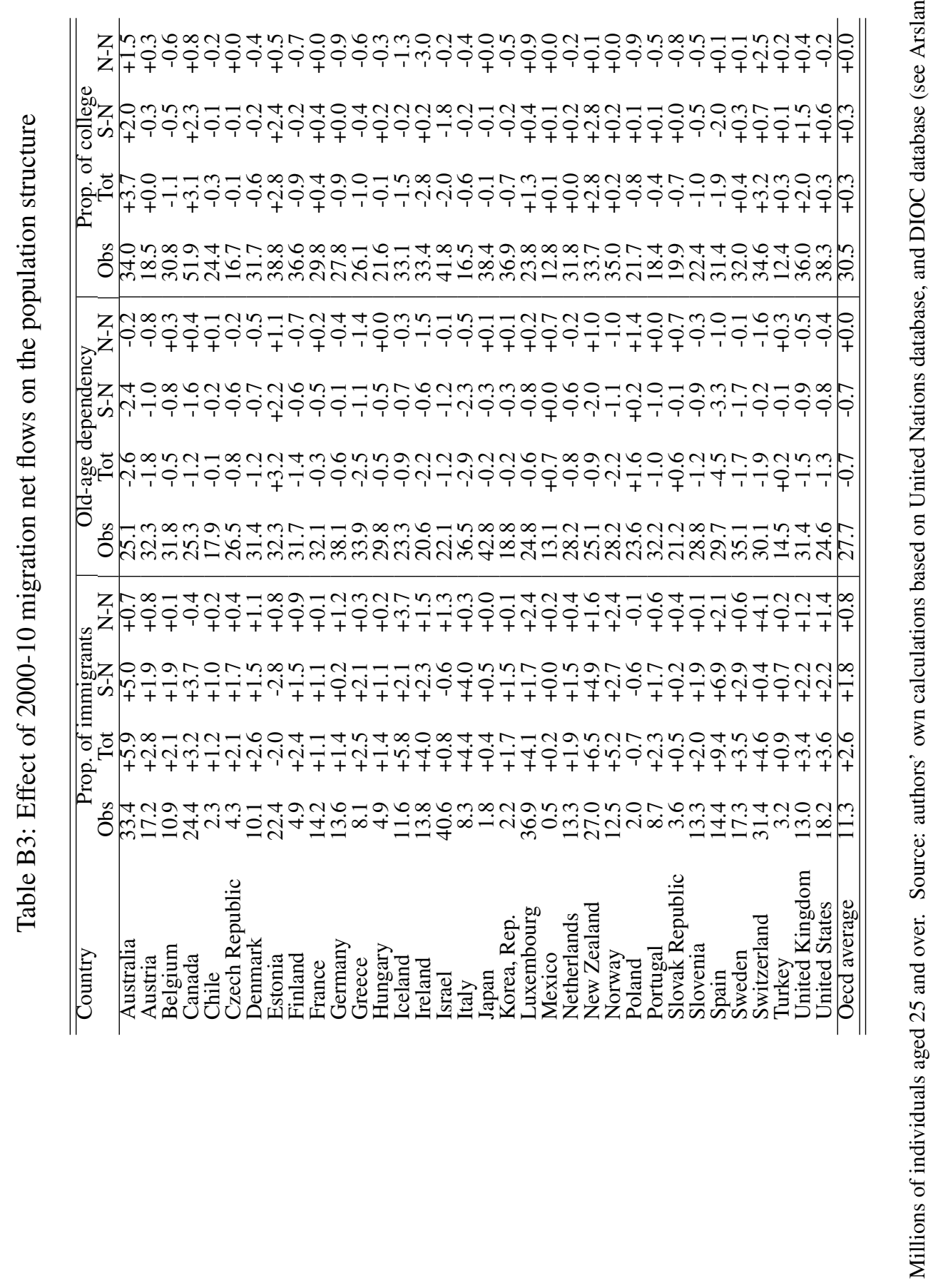




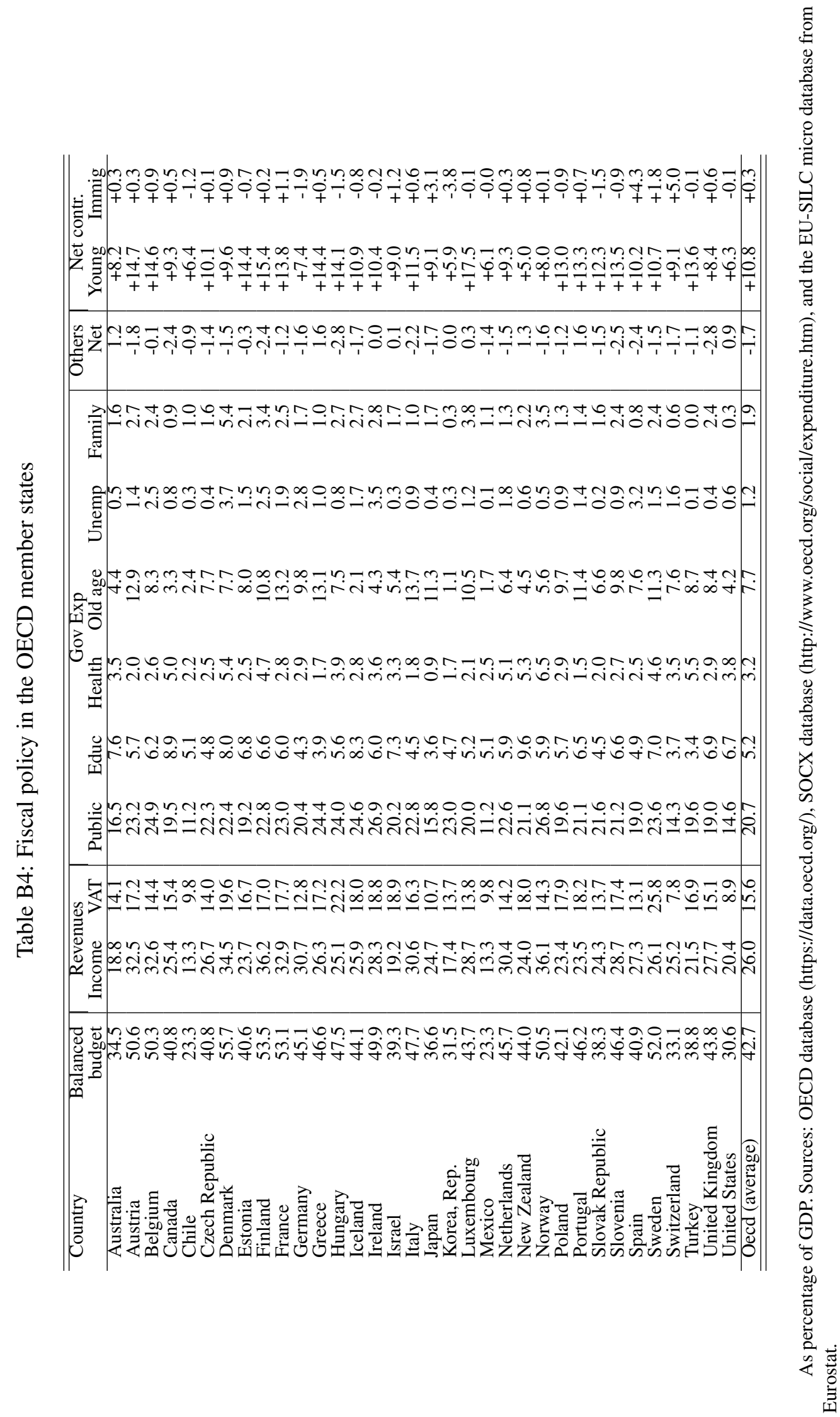



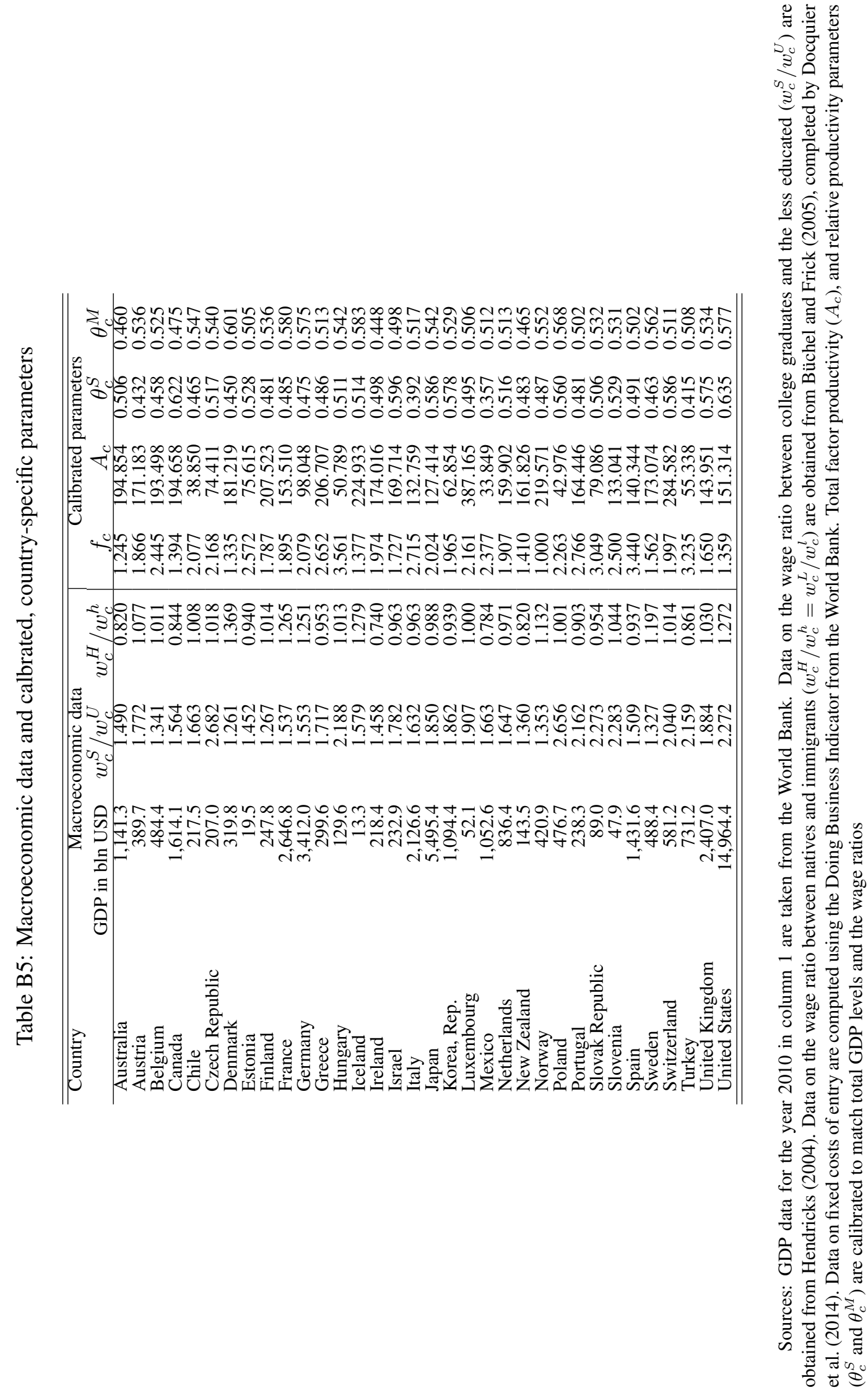


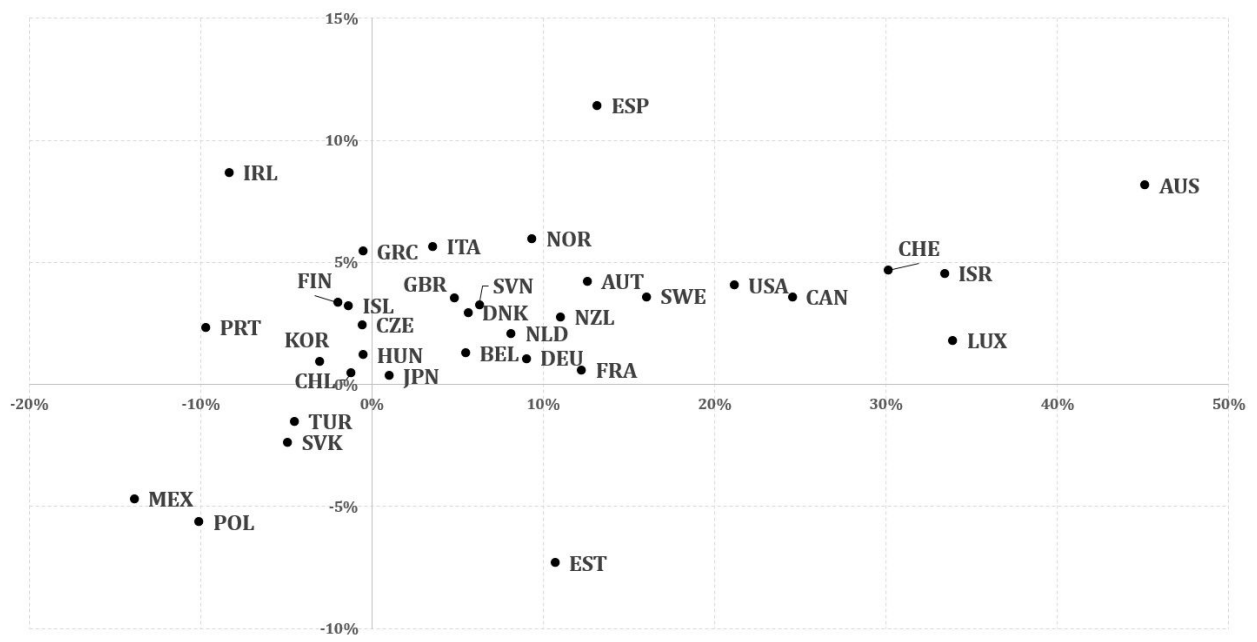

(a) Effect on population size

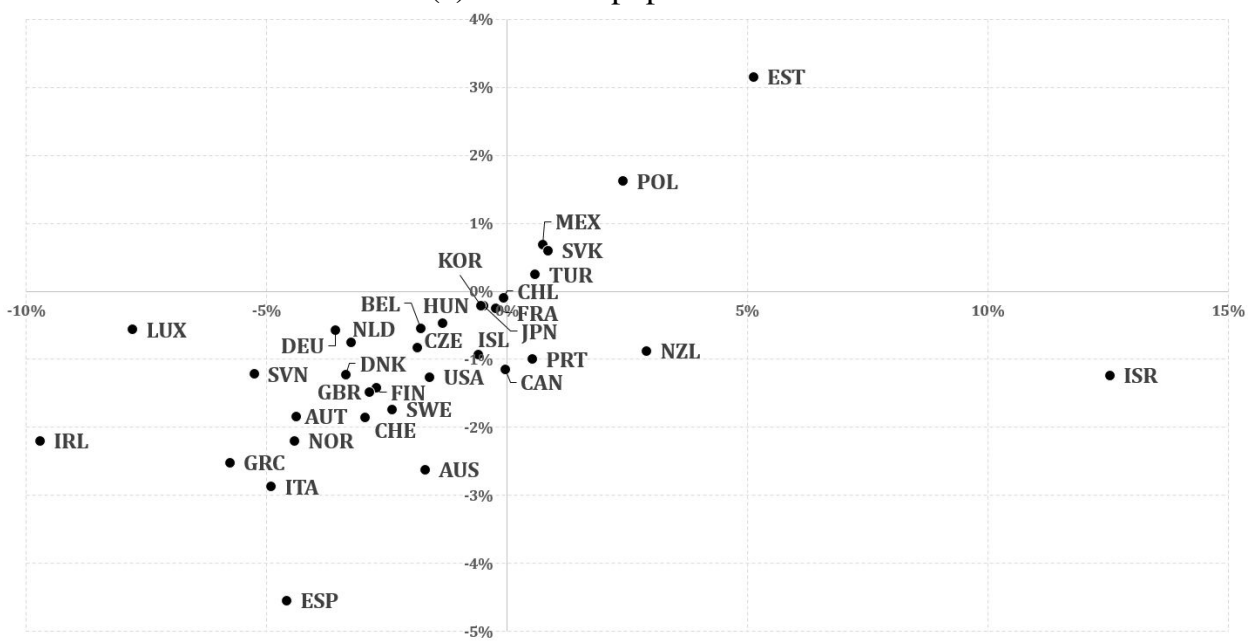

(b) Effect on the dependency ratio

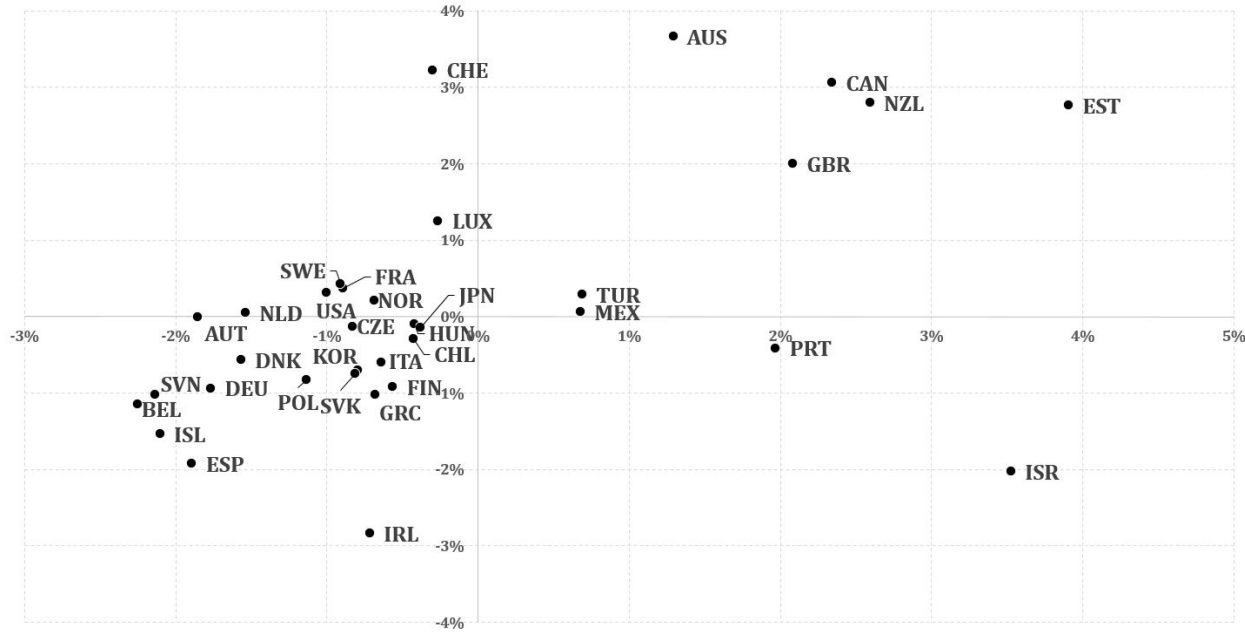

(c) Effect on the proportion of college graduates in the labor force

Figure B1: Socio-demographic impact of 2010 migration stocks (X-axis) and 2000-10 migration flows (Y-Axis) as percentage of deviation from the no-migration counterfactual. 


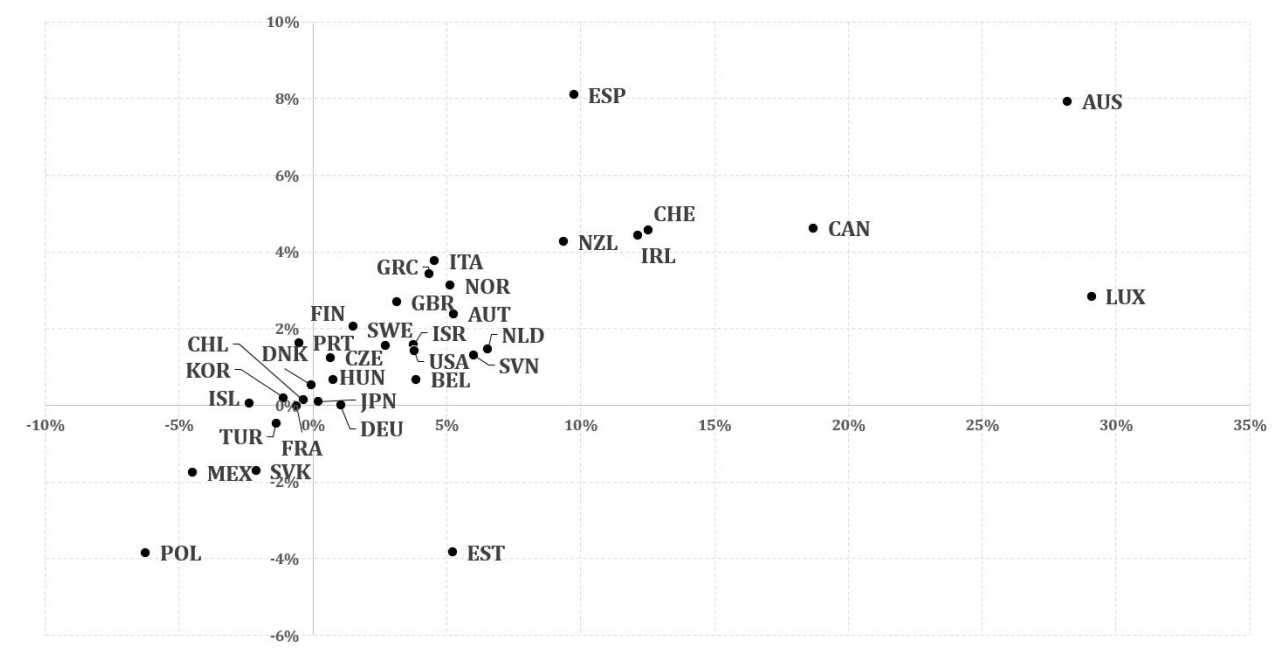

Figure B2: Average welfare impact of 2010 migration stocks (X-axis) vs 2000-10 migration flows (YAxis) as percentage of deviation from the no-migration counterfactual. 